\title{
Las termas y el Suburbium marítimo de Baelo Claudia AVANCE DE UN RECIENTE DESCUBRIMIENTO
}

\author{
D. Bernal*, A. Arévalo*, A. Muñoz**, J.A. Expósito***, J.J. Díaz*, J. Lagóstena*, \\ J.M. Vargas*, M. Lara*, E. Moreno*, A.M. SÁEZ*, M. Bustamante* \\ *Universidad de Cádiz \\ ** Conjunto Arqueológico de Baelo Claudia
}

Recibido: 08/11/2012

Revisado: $16 / 11 / 2012$

RESUMEN

Entre los años 2010 y 2012, la Universidad de Cádiz y la Junta de Andalucía han desarrollado investigaciones arqueológicas en la zona extramuros de la ciudad hispanorromana, en el marco del Proyecto General de Investigación "La economía marítima y las actividades haliéuticas en Baelo Claudia". Se presentan en esta sede los primeros resultados, que han permitido identificar la existencia de un suburbium occidental en la ciudad, entre el cauce del arroyo de las Villas, la playa y la necrópolis oeste, cuya existencia se ha podido confirmar por datos geofísicos y arqueológicos. En él han podido ser excavadas parcialmente unas estructuras que se han identificado con unas termas suburbanas, activas entre el s. II y el V d.C., habiéndose excavado una piscina del frigidarium y algunas estancias calefactadas, con hallazgos muy significativos como parte de la decoración marmórea y escultórica del complejo, que en época tardorromana fue amortizado intencionalmente por motivos posiblemente religiosos. Estos hallazgos son de gran interés, pues además de verificar la existencia de un segundo complejo balneario público en la ciudad plantean la importancia del poblamiento periurbano, una línea de investigación totalmente inédita hasta la fecha.

Palabras Clave

Baelo Claudia. Termas romanas. Suburbium. Prospecciones geofísicas.
ABSTRAC

Between the year 2010 and 2012, the University of Cadiz and the Regional Government (Junta de Andalucía) have developed archaeological activities in the zone outside the hispano-roman city, in the frame of the General Project of Research titled "The maritime economy and the halieutic activities in Baelo Claudia". We are presenting in this paper the first results, which have allowed to identify the existence of a western suburbium outside the city, between the riverbed of the so called "arroyo de las Villas", the beach and the western necropolis, whose remains have been confirmed by geophysical and archaeological techniques. Inside this area a few structures have been excavated, identified as a Roman baths complex, active from the 2 nd up to the $5^{\text {th }}$ century a.D. A big pool, part of the frigidarium and some heated rooms have been unearthed, with very significant findings as part of the marmoreal and sculptural decoration of the complex, which in late roman times was intentionally broken into pieces possibly by religious motives. These findings are of great interest, since beside confirming the existence of the second public thermae of the city they raise the importance of the peri-urban buildings, a new line of research up to date.

\section{KEYWORDS}

Baelo Claudia. Roman baths. Suburbium. Geophysical survey. 
“...et l'on peut objecter la rareté, sinon l'absence, des piscines monumentales à l'époque romaine en dehors des bains publics et des thermes"

(Paris et alii, Fouilles de Belo I, 1923, 106)

\section{INTRODUCCIÓN ${ }^{1}$}

Desde el año 2010 la Universidad de Cádiz desarrolla el Proyecto General de Investigación (en adelante PGI) denominado "La economía marítima y las actividades haliéuticas en Baelo Claudia. Problemas de atribución funcional en el barrio meridional", autorizado por la Consejería de Cultura de la Junta de Andalucía y desarrollado en colaboración con el Conjunto Arqueológico de Baelo Claudia, vigente durante un sexenio.

En el desarrollo del Plan Director de Baelo Claudia, este proyecto se enmarca en el estudio y valorización de la industria pesquera-conservera de la ciudad, uno de los aspectos fundamentales de su razón de ser y su singularidad, tratando a medio plazo de avanzar en el conocimiento histórico de la ciudad y permitir una mayor comprensión de los restos inmuebles conservados, facilitando su integración en los itinerarios de visita. En concreto, este PGI deriva y constituye el natural desarrollo del estudio precedente acometido entre los años 2000 y 2004 en el barrio meridional de la ciudad hispanorromana, en el cual se actualizó la topografía urbana de los edificios de ámbito pesqueroconservero, habiéndose detectado la existencia de algunos inmuebles de uso/funcionalidad indeterminada, como era el caso de los denominados E.M. II, E.M. III o E.M. VIII (Bernal et alii, 2007, 188-210), actividades que continuaron hasta el año 2009, encontrándose estas últimas en fase de publicación actualmente. Como objetivos generales del proyecto, se trata de proceder a la delimitación del perímetro exterior del barrio meridional y de profundizar en el conocimiento de la articulación interna del mismo en insulae y/o edificios, estrategia extensible a la totalidad de la zona urbana localizada al sur del Decumanus Maximus; y de determinar la funcionalidad de algunos ámbitos totalmente excavados a techo de muro, e integrados en el circuito de visita. Indicar, por último, que también se aspira a conti-

1 Este trabajo se enmarca en el curso de desarrollo del proyecto SAGENA (HAR2010-15733), del Plan Nacional I+D+i y del PGI "La economía marítima y las actividades haliéuticas en Baelo Claudia” (Universidad de Cádiz - Junta de Andalucía). nuar la línea de estudio sobre las cetariae, la pesca y la industria conservera baelonense, habiendo sido éste el tema neurálgico de interés de la Universidad de Cádiz desde el inicio de las investigaciones arqueológicas en este yacimiento (Arévalo y Bernal, 1999, 2006 y 2007, eds.; Bernal, 2011, ed.).

En este trabajo se presentan los primeros resultados de las investigaciones realizadas entre los años 2010 y 2012 en el área localizada al oeste del arroyo de las Villas ${ }^{2}$, en la cual existían una serie de estructuras emergentes (figura $1 \mathrm{~A}$ ), sobre las cuales no se había intervenido en ningún momento, y cuyo aislamiento de la topografía de la ciudad y del actual circuito de visitas era manifiesto (figura $1 \mathrm{~B}$ ), lo que aconsejaba su evaluación para una futura integración en el itinerario visitable. El hecho de tratarse de un supuesto edificio aislado, junto a otros factores que analizaremos con detalle a continuación, habían hecho plantear la hipótesis de que el mismo se pudiese corresponder con un posible faro o thynnoskopeion/avistadero de túnidos (Bernal, 2009, 103-104), llegando incluso a plantear dicho paisaje cultural en la reconstrucción ideal de esta zona extramuros de la ciudad (figura $1 \mathrm{C}$, según Alonso et alii, 2007, 537, fig. 16). Como veremos a continuación, los resultados de las actividades arqueológicas acometidas hasta la fecha en este sector extra moenia de la ciudad han confirmado la existencia de una gran área periurbana, que consideramos un suburbium marítimo por su localización entre la ciudad y la playa, además de haber individualizado en su interior un complejo balneario, del cual se presentan los primeros testimonios en este trabajo.

\section{EL SUBURBIUM MARÍTIMO DE LA CIUDAD. CARACTERI- ZACIÓN Y DELIMITACIÓN}

La zona localizada al oeste del arroyo de las Villas ha sido tradicionalmente considerada como

2 Desde los trabajos de síntesis de P. Sillières $(1997,189)$ se ha denominado en la bibliografía a este curso de agua que rodea la ciudad por el oeste como "de las Viñas". Nosotros utilizamos la denominación "de las Villas" pues es ésta la que se mantiene en la tradición oral local (como recuerdan miembros de la familia Otero) y además se puede contrastar en la cartografía (Planimetría Digital de la Consejería de Obras Públicas y Transporte. Junta de Andalucía. Instituto de Cartografía de Andalucía. Mapa Topográfico de Andalucía 1:10.000. Provincia de Cádiz. ISBN 84-8095-303-9; № Registro: JAOP/CA-21-2002; Deposito Legal: SE-1.866-2002. Imagen h107712; Planimetría de la Ensenada de Bolonia. Escala 1: 5.000. Centro de Estudios Territoriales y Urbanos. Consejería de Obras Públicas y Transporte. Junta de Andalucía. Vuelo Escala 1:18.000, junio 1990). 


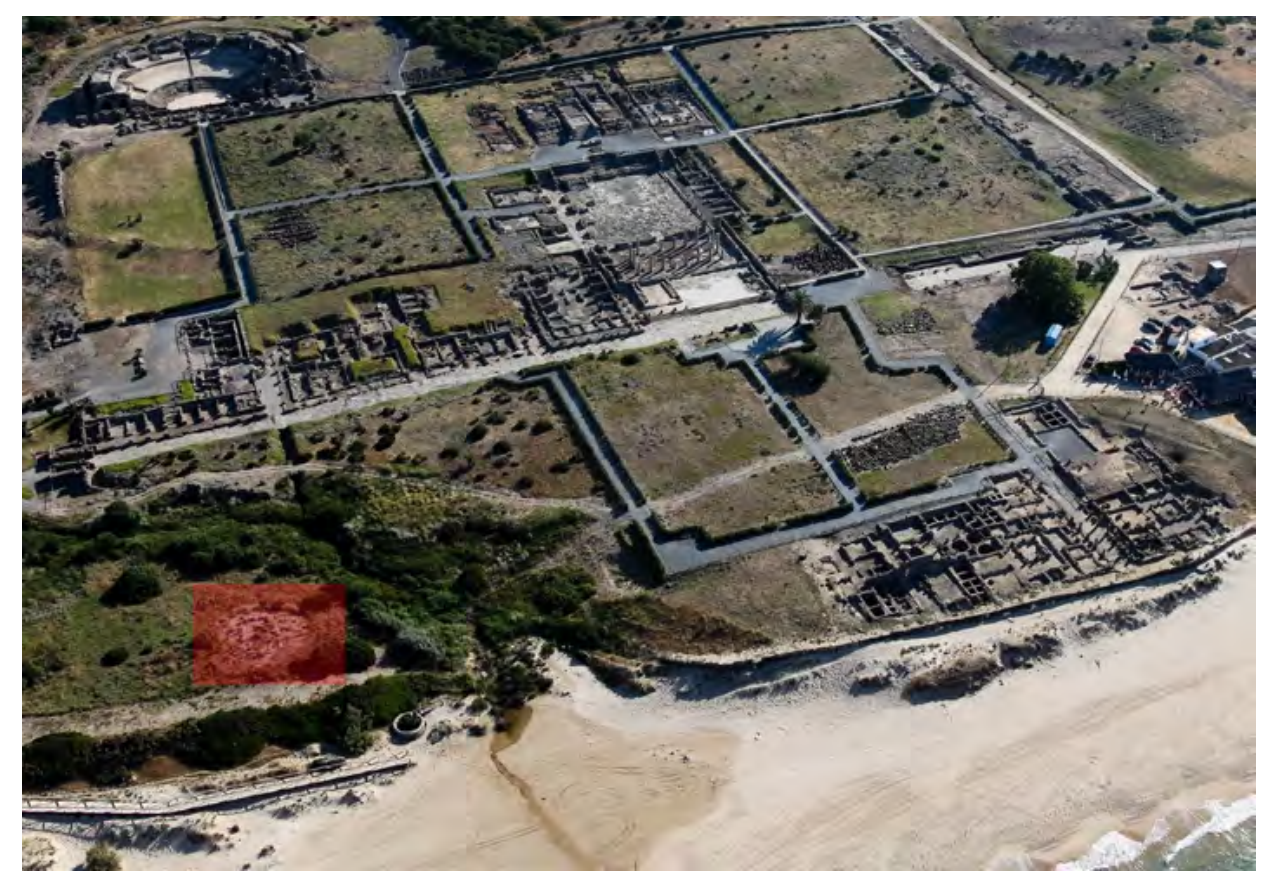

Figura 1. A

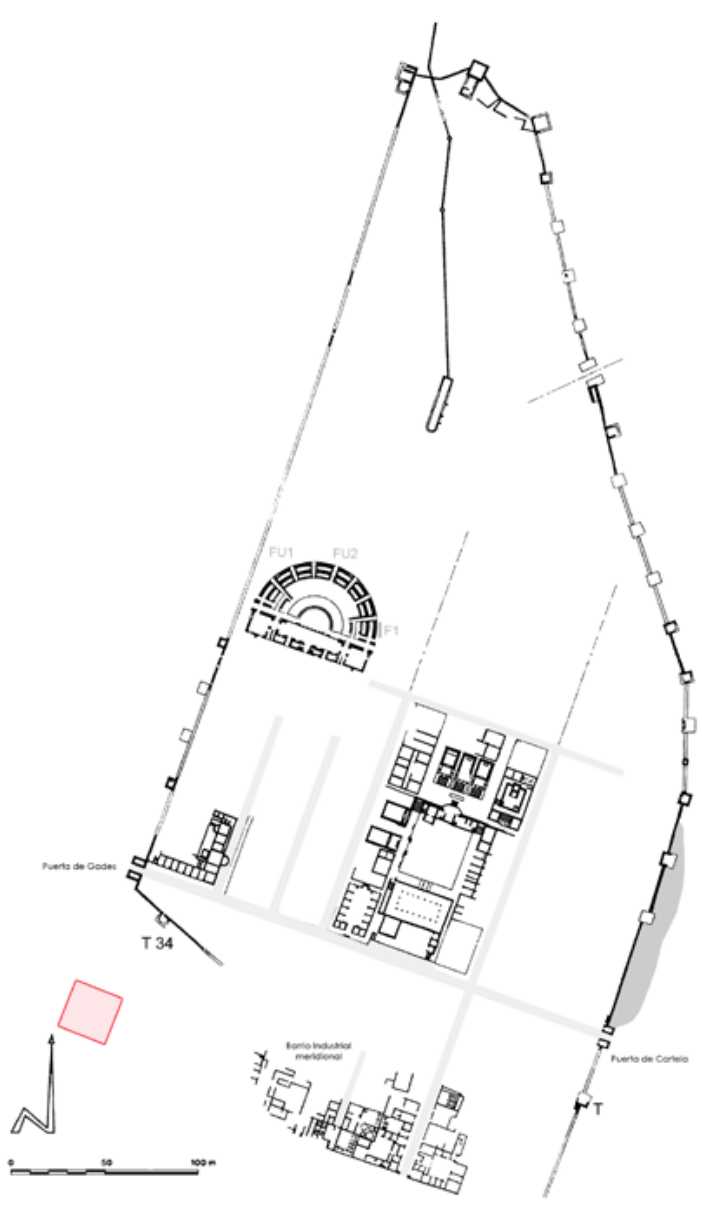

Figura 1. B

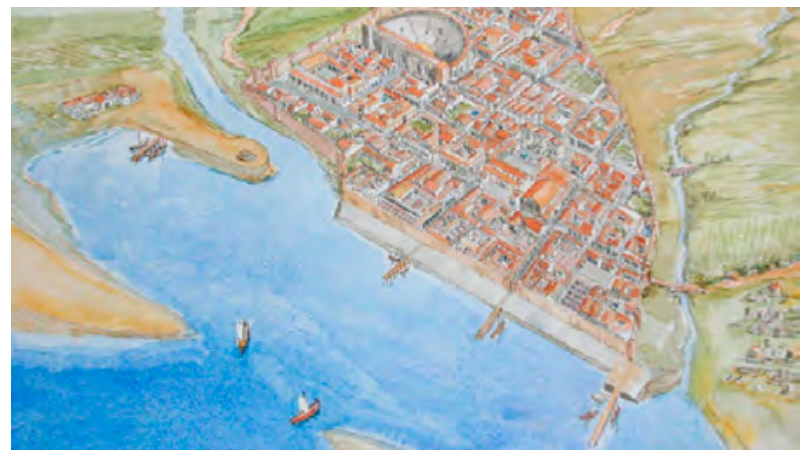

Figura 1. C
Figura 1. Vista aérea con la localización de las estructuras al oeste del arroyo de las Villas (A), con detalle de las mismas en relación a la planimetría de la ciudad de Baelo Claudia (B), y reconstrucción de la zona occidental (C.según Alonso et alii, 2007, fig. 16). 
parte de la necrópolis occidental de la ciudad, excavada parcialmente por el jesuita J. Furgus a unos trescientos metros de la Puerta de Gades y cuyo inicio "debía extenderse más cerca de la ciudad y comenzar poco después del arroyo de las Viñas" (Sillières, 1997, 189). La total ausencia de actividades arqueológicas en la zona, a excepción de algunas trincheras realizadas en su momento por P. Paris sobre las cuales luego volveremos, había provocado que esta parte de Baelo Claudia cayese en el olvido, no siendo nunca representada en la topografía publicada de la ciudad, considerando que al quedar extramuros debía constituir un ámbito periurbano vinculado, como decimos, al mundo funerario.

La atención prestada en el ámbito del PGI sobre la economía marítima de Baelo Claudia derivaba de la posible interpretación de este edificio exento con un faro. A favor de dicha hipótesis contábamos con la constatación de que el mismo constituía un edificio rectangular aislado de unos $50 \mathrm{~m}^{2}$ de superficie, ubicado sobre una paleo-elevación en primera línea de playa (a unos 6-7 mts. circa sobre el nivel del mar), que en función de los estudios geo-arqueológicos realizados parecía una pequeña isla sobreelevada sobre el terreno circundante (Alonso et alii, 2007). Con potentes muros perimetrales (de en torno a un metro de potencia), daba la impresión de que podría tratarse de la cimentación de un edificio de cierto porte, lo que unido a la total ausencia de edificaciones en las inmediaciones cuadraba con la posibilidad de que se tratase de un faro, planteando su posible dualidad como torre para el avistamiento de atunes, ante la importancia de las pesquerías y almadrabas que debió tener la ciudad hispanorromana, hipótesis planteada en su momento (Bernal, $2009,103)$. A pesar de su interés, carecíamos de información arqueológica fiable para avanzar sobre su determinación funcional, pues en el mismo o en su entorno más inmediato no había sido realizada intervención arqueológica alguna en fechas recientes.

En el mes de octubre del año 2010, y en el marco de la Fase I de las actividades del PGI, se acometió una prospección geofísica en el barrio meridional de la ciudad y en el sector al oeste del arroyo de las $\mathrm{Vi}-$ llas objeto de atención ahora ${ }^{3}$, a cargo de la empresa Eastern Atlas (Meyer, 2010). Cuestiones de índole

3 Autorizada por la Dirección General de Bienes Culturales de la Consejería de Cultura de la Junta de Andalucía por Resolución de 7 de julio de 2010, y dirigida por uno de los miembros del equipo (J.J.D.). presupuestaria limitaron la zona de intervención al sector oriental del barrio meridional -entre el posible cardo maximus y las instalaciones exteriores a la delimitación oriental, siendo sectorizada la zona por la complejidad de acceso-, así como a un área en torno al edificio al oeste del arroyo de las Villas (figura 2, sector L), siendo en total la zona intervenida de unos nueve mil metros cuadrados, ya que cinco mil aproximadamente de los inicialmente planteados no fueron practicables.

$\mathrm{La}$ prospección geofísica fue realizada con georadar, utilizando un equipo GSSI SIR-3000, dotado de una antena de $270 \mathrm{MHz}$., con una distancia de perfiles de $0,5 \mathrm{mts}$. Los datos fueron registrados en perfiles cubriendo la totalidad de la superficie objeto de estudio, cuyo procesado y lectura posterior ofrece ocho secciones horizontales (figuras 3 y 4), que representan respectivamente capas del subsuelo con una potencia aproximada de $30 \mathrm{cms}$. cada una entre la superficie y la profundidad máxima de lectura alcanzada $(2,4 \mathrm{mts}$.). La existencia de suelos naturales de naturaleza arenosa, y estructuras y pavimentos antrópicos con derrumbes provocó una baja absorción de las ondas electromagnéticas, por lo que las lecturas han sido bastante profundas, llegando aproximadamente a los 2,5 mts. No obstante, en este yacimiento diversos elementos ambientales dificultaron el trabajo, como la escasa homogeneidad de la matriz del subsuelo, resultado de un asentamiento con múltiples ocupaciones a lo largo del tiempo, lo que se traduce en superposiciones de estructuras diversas (además construidas con materiales diferentes) alternantes con capas deposicionales de derrumbes y otra naturaleza que provocan la dispersión de las ondas de georadar debido a la cantidad de superficies reflejadas en el suelo. Este efecto se manifiesta en datos borrosos, de compleja interpretación, con superposiciones de reflexiones de intensidad variable que vuelven compleja su hermenéutica. Asimismo, la presencia de vallados y estructuras modernas ha obligado a la división del área investigada en retículas individuales de reducidas dimensiones ( 24 en el barrio meridional), lo que disminuye la coherencia en la interpretación (Meyer, 2010).

El área investigada que nos interesa ahora, denominada con la letra L (figura 2, izda.), constituye un polígono irregular, de unos $2000 \mathrm{~m}^{2}$, cuya singular morfología deriva de la existencia de desniveles y piedras sueltas en superficie durante la prospección, a pesar de que todo el sector fue in- 
tensamente desbrozado previamente a la ejecución de los trabajos de campo. Como se puede advertir en los planos (figuras 2,3 y 4 ), se han representado los muros septentrional y occidental emergentes del citado edificio (sin trama interna), habiéndose prospectado especialmente hacia el norte, sur $\mathrm{y}$ ante todo hacia el oeste de dichos paramentos, aprovechando la zona llana amesetada de la parte alta del promontorio y los calveros sin vegetación.

$\mathrm{La}$ interpretación que podemos hacer de los resultados geofísicos resulta de gran interés para la comprensión del cerro sobre el cual se asienta el pequeño edificio, y para aclarar muchos interrogantes sobre esta zona de la ciudad. Valorando las ocho secciones horizontales de manera combinada (figuras 3 y 4), podemos concluir al menos los siguientes aspectos.

El primero y más evidente es que el edificio emergente no constituye un elemento aislado en dicho cerro, ya que hay estructuras arquitectónicas de notable entidad (tramas lineales opacas en las figuras), asociadas a potentes niveles de derrumbe (polígonos con reticulado interno en las ilustraciones) por toda la superficie investigada (como ilustra la figura $3 \mathrm{D}$, por ejemplo). Es decir, había que descartar que el supuesto "faro" constituyese una construcción aislada, más bien la misma se asociaba a otros complejos edilicios. Incluso la densidad de estructuras debe ser mucho mayor que la reflejada en la interpretación de las lecturas de los datos del georadar (figuras 3 y 4), pues, como decimos, hay zonas, como el área central del sector investigado, que no han aportado datos al haber sido inaccesibles durante la campaña de prospección (figura 5, áreas en blanco).

En segundo término, que las estructuras se proyectan mucho más allá del área objeto de investigación geofísica, ya que se localizan bien muros o derrumbes cortados o coincidentes con el final de las áreas objeto de estudio con el georadar tanto al norte (figuras $3 \mathrm{C}, 3 \mathrm{D}$ y $4 \mathrm{C}$ ) como al este (figuras $3 \mathrm{~A}, 3 \mathrm{D}, 4 \mathrm{~A}, 4 \mathrm{C}$ ) y al oeste (figuras 3 y 4 comple-

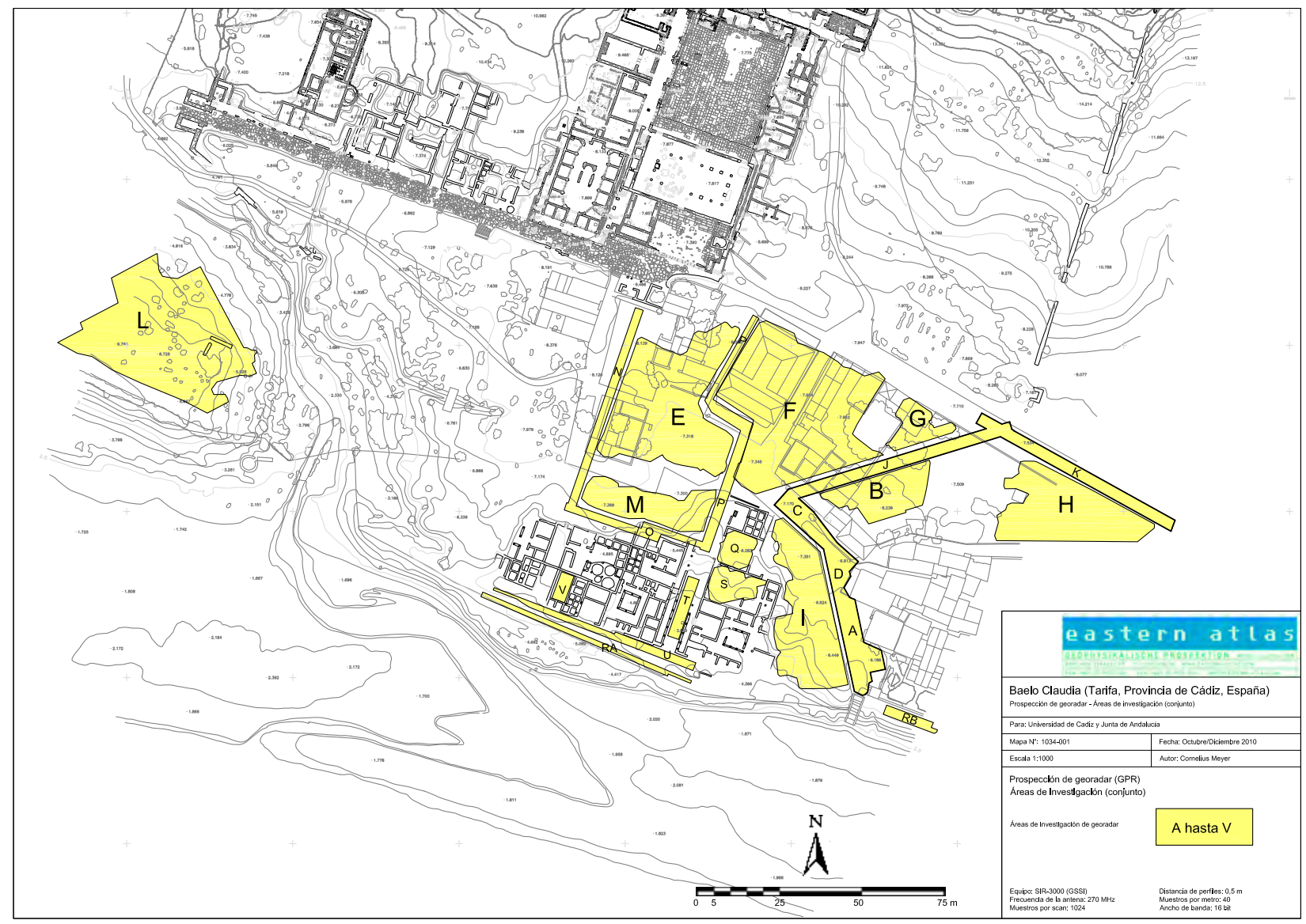

Figura 2. Planimetría de Baelo Claudia con la localización de las áreas objeto de prospección geofísica durante el año 2010 (polígonos opacos numerados con las letras A a V). 

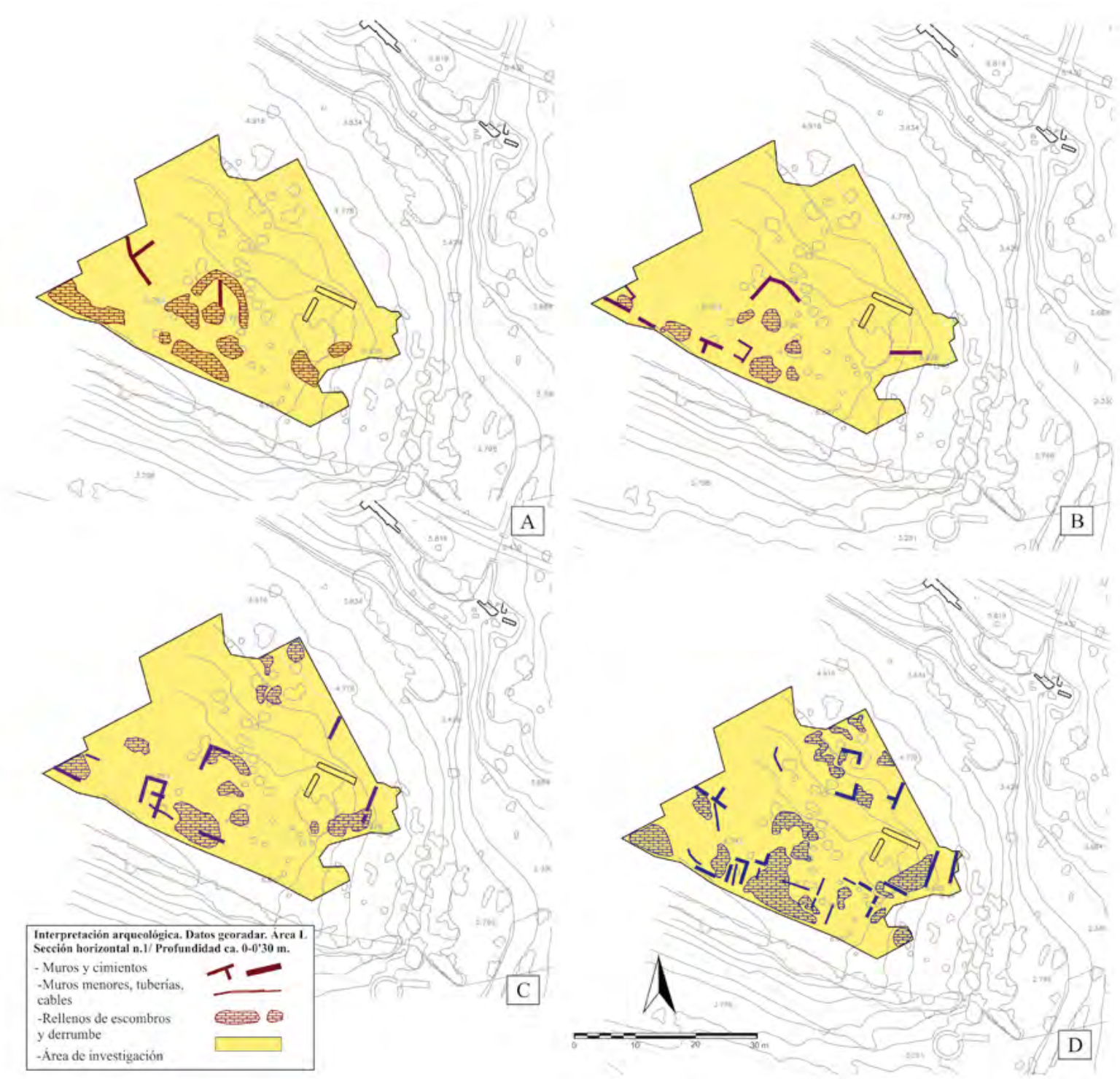

Figura 3. Planos con la interpretación de los resultados de la prospección con georadar en el área al oeste del arroyo de las Villas, con lecturas cada $30 \mathrm{cms}$. de profundidad (A.- 0-30 cm.; B.- 30-60; C.- 60-90; D.- 90-120; Meyer, 2010, BC1034211 a BC1034214).

tas). Al sur, además de los resultados de la geofísica, especialmente derrumbes proyectados a todo lo largo de esta zona, contamos adicionalmente con la existencia de un gran muro sobre un amasijo de opus caementicium, de notable entidad, al exterior del vallado perimetral del yacimiento, junto a la pasarela de la playa (figura 6), que confirma la prolongación de las estructuras en dicha dirección. Todo ello permite verificar que en el entorno amesetado situado al oeste del arroyo se localiza una concentración de estructuras de notable entidad, cuyas dimensiones no resulta posible determinar con precisión sin realizar una prospección geofísica con sondeos de comprobación. No obstante, y valorando la extensión de la meseta hasta la aparición del cambio de rasante del terreno e inicio del pinar -que podría estar determinando el inicio de la necrópolis occidental excavada parcialmente por Furgus- estamos hablando de una superficie mínima aproximada de una hectárea $(200 \mathrm{mts}$. aprox. E-O por $50 \mathrm{~N}-\mathrm{S}$ ), lo que da una idea de la entidad del área geográfica objeto de análisis.

Otro elemento a tener en cuenta es la gran densidad de estructuras que parecen documentarse en 

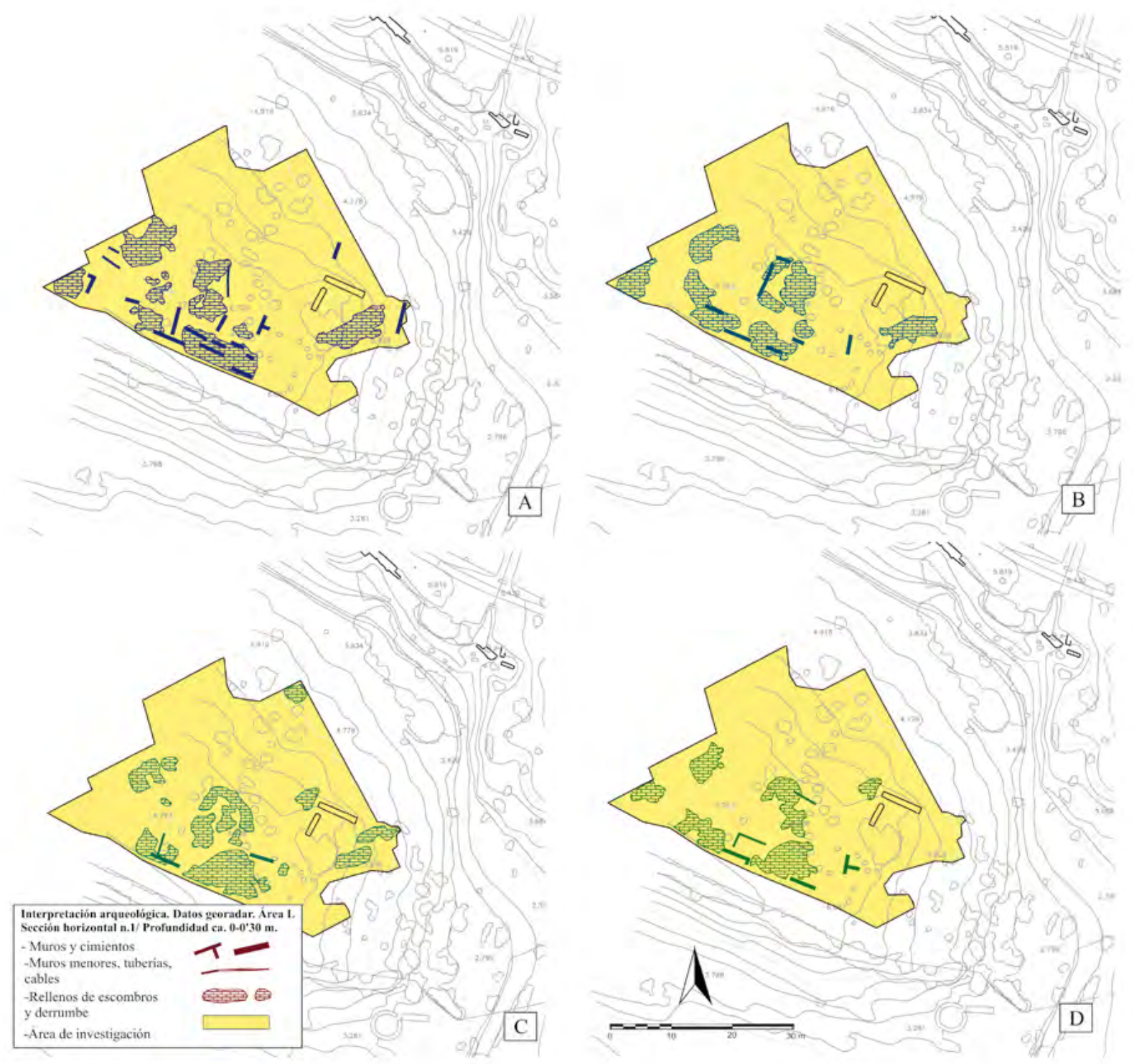

Figura 4. Planos con la interpretación de los resultados de la prospección con georadar en el área al oeste del arroyo de las Villas, con lecturas cada $30 \mathrm{cms}$. de profundidad (A.- 120-150; B.- 150-180; C.- 180-210; D.- 210-240; Meyer, 2010, BC1034215 a BC1034218).

el interior del área analizada por georadar, de lo que parece deducirse que no se trata de unidades murarias aisladas sino verdaderamente de una auténtica trama urbanizada. Especialmente significativas a estos efectos parecen las lecturas en torno al metro o metro y medio de potencia, en cada una de las cuales se han individualizado 25 y 17 nuevas estructuras murarias respectivamente (figuras $3 \mathrm{D}$ y $4 \mathrm{~A})$, bajo las correspondientes áreas de derrumbe que pueden estar enmascarando otras. De ahí que pensemos en la existencia de edificios y ambientes con varias habitaciones más que en un poblamiento disperso y atomizado.

Otro aspecto a tener en cuenta en las lecturas interpretadas del georadar es la notable potencia de los restos hallados que, como hemos indicado, al menos se desarrollan a lo largo de la totalidad de los 2,5 mts. de profundidad que han dado resultados de lectura. En las diversas secciones horizontales se advierte cómo algunas estructuras, con sus correspondientes derrumbes, aparecen y desaparecen, documentándose otros restos más abajo, de lo que es fá- 


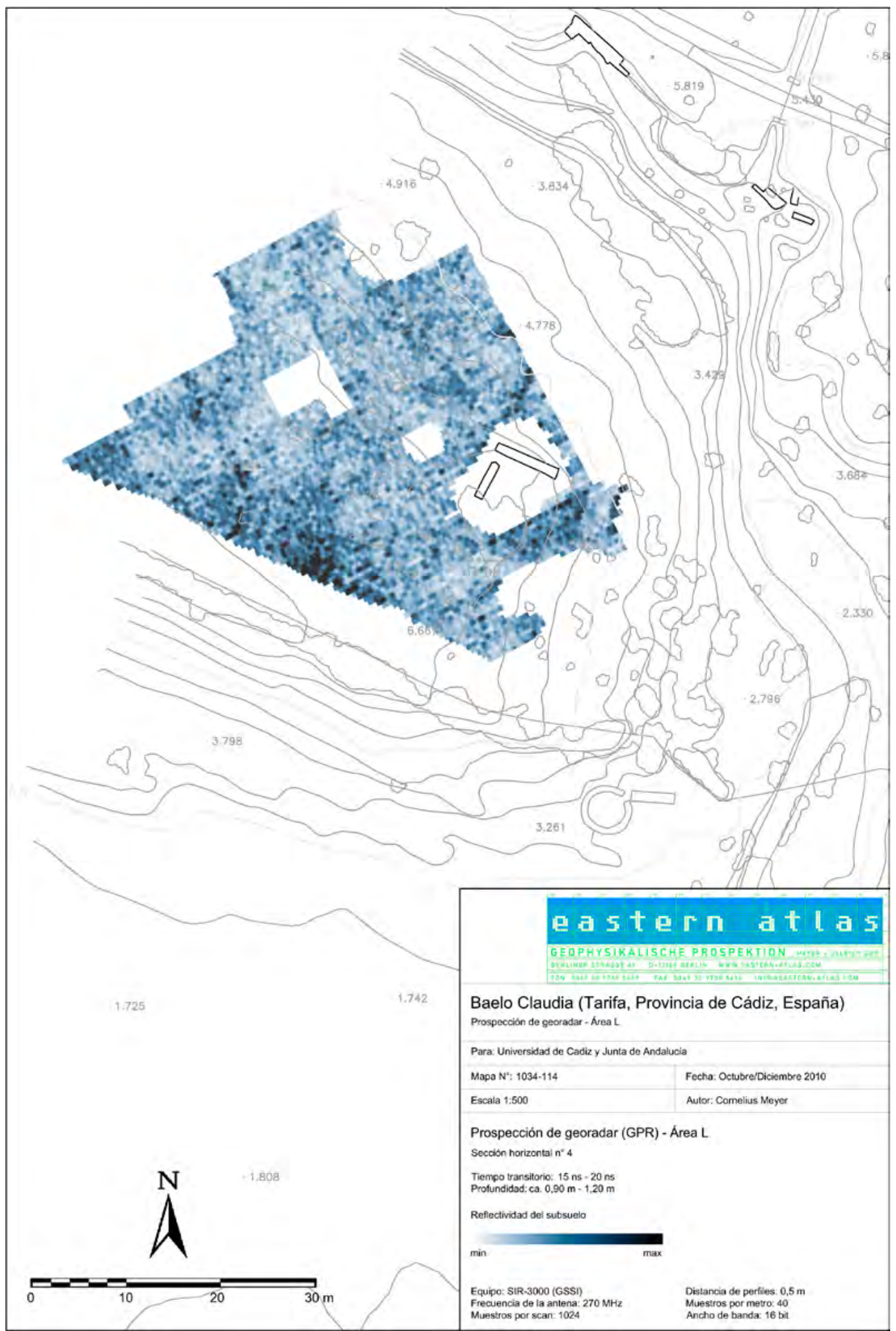

Figura 5. Mapa de la reflectividad del subsuelo (más oscuro, mayor) del área L, a una profundidad entre 0,9 y 1,2 mts. (Meyer, 2010, sección horizontal 4, mapa BC1034-114). 


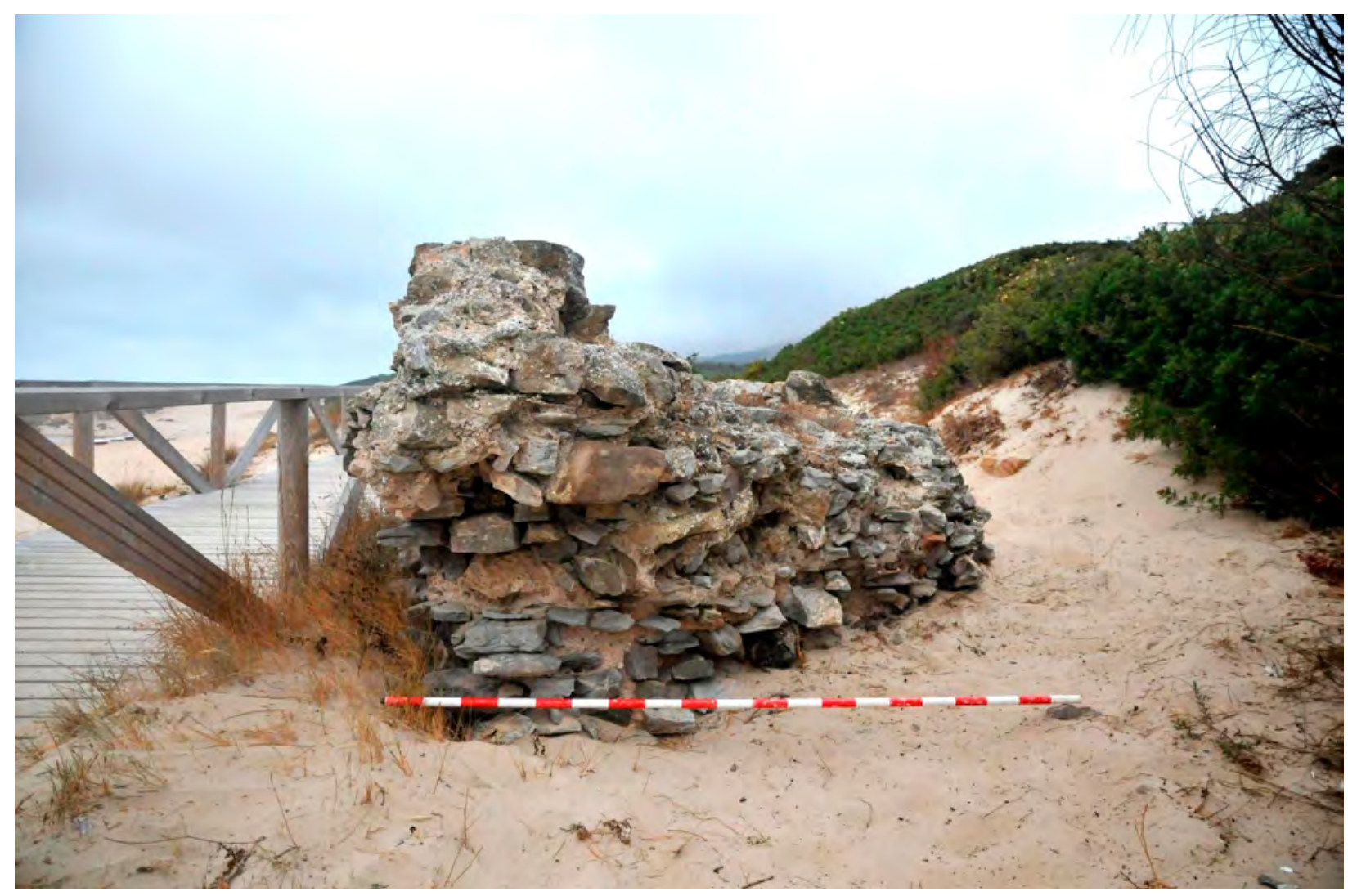

Figura 6. Caementa y restos de estructuras arquitectónicas de notable porte al sur del área objeto de estudio, junto a la pasarela de la playa.

cil inferir la existencia de varias fases constructivas. Así se confirma, por ejemplo, en el ángulo suroeste del Área L, en el cual inicialmente contamos con un derrumbe (figura $3 \mathrm{~A}$ ), bajo el cual aparecen estructuras (figura $3 \mathrm{~B}$ y C), volviéndose a una cota inferior a documentar otro derrumbe, aparentemente de gran entidad (figuras $3 \mathrm{D}, 4 \mathrm{~A}, 4 \mathrm{~B}$ ), el cual vuelve a desaparecer (figura 4C), documentándose al final de la secuencia, ya a más de dos metros de potencia, otro nuevo nivel deposicional con restos de escombros-derrumbes (figura 4D). Algo, por otro lado, evidente, ya que el estado de conservación de las estructuras en la ciudad no suele llegar a una dimensión media superior al metro de altura, salvo excepciones (muralla, muros de aterrazamiento o cimentaciones/alzados de edificios públicos).

No resulta ni aconsejable ni prudente realizar una interpretación funcional de los restos sin haber procedido a una diagnosis arqueológica adicional, pues como ya hemos indicado anteriormente diversos factores han complicado la legibilidad de los resultados. No obstante, sí parece conveniente indicar, por analogía con la dinámica de ocupa- ción que conocemos en otras zonas de la ciudad, que es más que probable que existan estructuras de época romano-republicana en esta zona, situadas a bastante profundidad (en torno a los 2 mts. respecto a la cota actual, figuras $4 \mathrm{C}$ y $4 \mathrm{D}$ ). Recordamos que en el Sondeo 1 realizado bajo la pavimentación del Conjunto Industrial VI se documentó una secuencia con al menos 4 mts. de potencia y cinco horizontes constructivos -Fases IV a VIII- fechados en la segunda mitad del s. II a.C. , sin haber llegado a agotar la estratigrafía por el afloramiento del nivel freático (Bernal, Arévalo y Sáez, 2007, 264, fig. 40). Asimismo, en la parte superior de la secuencia (figura $3 \mathrm{~A}$ ), da la impresión de que algunas estructuras en la zona central $y$ centro-occidental del ambiente presentan una orientación discordante respecto a todas las demás, pudiendo corresponder a las fases bajo-imperiales o tardoantiguas. Por último, reseñar que da la impresión de que la mayor parte de las unidades murarias que aparecen definidas como tales presentan una orientación NE-SO (con sus correspondientes trazados perpendiculares), en general totalmente 


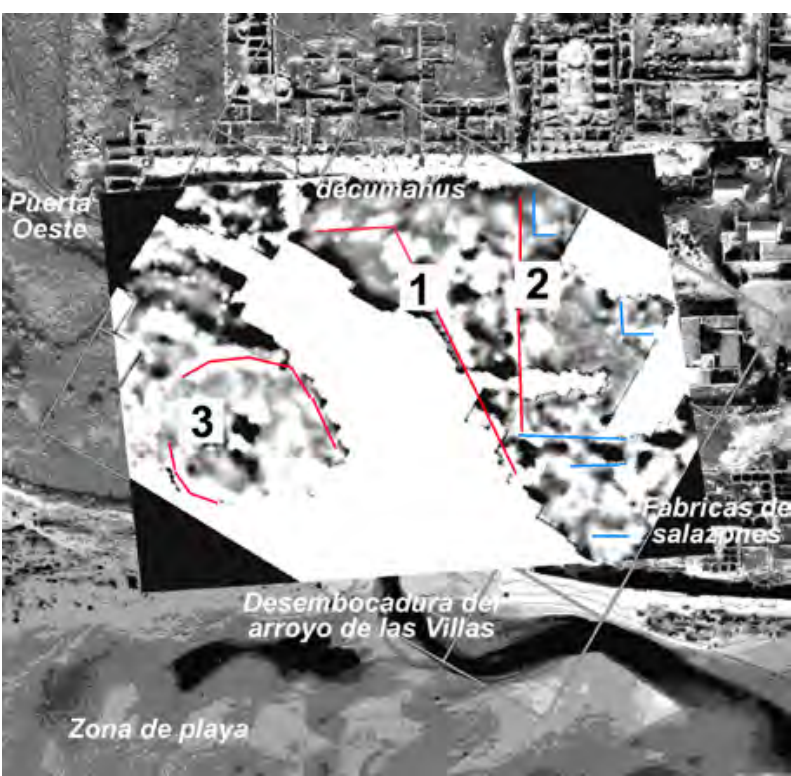

Figura 7. Resultados de la prospección geofísica realizada en el arroyo de la Villas entre 1999 y el año 2001 por técnicos del IAPH de la Junta de Andalucía (Alonso et alii, 2007, 526, fig. 3).

compatible con los ejes básicos del urbanismo de la ciudad intra moenia, dando la impresión de que el trazado de estas construcciones está íntimamente relacionado con el proceso de edificación de la ciudad altoimperial.

Por último, apuntar, como líneas de trabajo a desarrollar en el futuro, que la alineación de estructuras localizadas en la parte meridional del área investigada parece definir una especie de iter o via en dirección SE-NO, especialmente visible en los perfiles entre 1,2 y $1,8 \mathrm{mts}$. (figuras $4 \mathrm{~A}$ y $4 \mathrm{~B}$ ); así como la posible existencia de un edificio o habitación de grandes dimensiones en el sector central del área investigada (figura $3 \mathrm{~B}, 3 \mathrm{C}$ y 4 B), aparentemente similar en dimensiones a las estructuras emergentes conocidas previamente en la zona.

A estos datos hay que sumarles los conocidos previamente, derivados de las investigaciones de otros autores. De una parte, se trata de una posible estructura circular de grandes dimensiones identificada en esta zona, a la cual estaría circunscrita la emergente visible en la actualidad, tal y como los resultados de otra prospección geofísica, mediante técnicas magnéticas y de resistividad eléctrica, pusieron de manifiesto (Alonso et alii, 2007, 526, fig. $\left.3, n^{\circ} 3\right)$. Se trata de un círculo u óvalo, sin cerrar en su parte suroriental, de compleja interpretación, que habrá que tratar de localizar arqueológicamente en el futuro mediante sondeos arqueológicos ${ }^{4}\left(\mathrm{fi}^{-}\right.$ gura 7).

Además de ello, conviene traer a colación unas estructuras localizadas por P. Paris a inicios del siglo pasado en esta zona, y que constituyen posiblemente una de las problemáticas arquitectónicas más importantes de Baelo Claudia: se trata del denominado por el hispanista francés "édifice indéterminé: amphithéatre ou nymphée" (Paris et alii, 1923, 99-110, pl. XVII y XVIII). La importancia de los hallazgos indujo a estos investigadores a inicios del s. XX a dedicar en el volumen I de las Fouilles de Belo un capítulo monográfico (el $\left.\mathrm{n}^{\mathrm{O}} \mathrm{VI}\right)$ a este monumento, tratándose actualmente de la única gran área excavada por ellos en la ciudad hispanorromana cuya funcionalidad resta indeterminada, y sobre la cual los diversos investigadores con posterioridad no han vuelto a incidir.

En primer lugar, los datos sobre su localización restan imprecisos: según P. Paris, se sitúa "à une centaine de mètres à l'ouest et en dehors de l'enceinte, et tout près de la plage, à l'endroit où débouche par une trouée de la dune, au pied d'un cortijo abandonée, un arroyo presque complètement à sec (pl. XVII)". Es evidente que todas estas indicaciones coinciden con el ámbito situado al oeste del arroyo de las Villas, si bien algunas de las imágenes publicadas (figuras $8 \mathrm{~A}$ y D) permiten valorar que posiblemente se sitúe más al noroeste del área excavada, pues en ellas se advierte que los restos están bastante al oeste de una choza ${ }^{5}$, cuyos restos no se conservan y que en cualquier caso confirman que no se localizaba justo sobre el cauce del arroyo, ya que la vegetación de fondo visible indica el paleocauce del curso de agua. Por otra parte, la ausencia de restos de edificaciones de gran amplitud y de trazado elíptico en las geofísicas confirma indirectamente que no hemos localizado dichos restos excavados por el equipo franco-español ${ }^{6}$.

Respecto a la interpretación de la principal estructura excavada (figura $8 \mathrm{~A}$ ), tanto en 1919 como en 1921, interesa destacar que la misma está hueca

4 Que quizás corresponda, en parte, con las estructuras superficiales de trayectoria curvilínea identificadas al oeste del área que investigamos con técnicas geofísicas (figura 3 a).

5 Una de las posibilidades es que la reocupación contemporánea de la habitación denominada $\mathrm{H}-1$, que luego veremos, se corresponda exactamente con dicha vivienda.

6 Actualmente se está trabajando sobre el material documental y gráfico de las antiguas excavaciones para intentar precisar al respecto. 

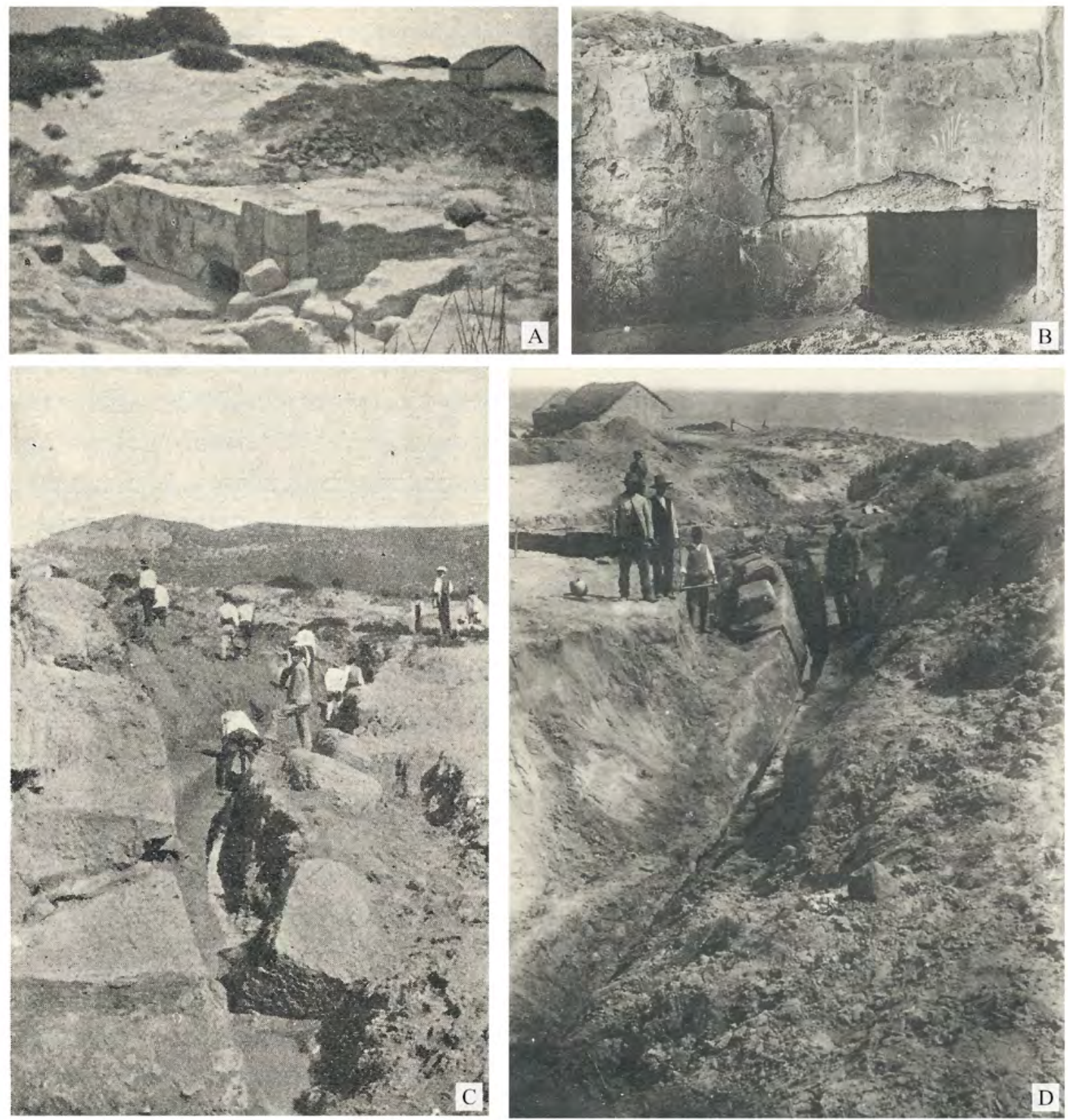

Figura 8.- Estructuras exhumadas por P. Paris al oeste del arroyo de las Villas (Paris et alii, 1923, 101, fig. 32 -A-; lám. XVII -B-; 104, fig. 33 -C- y lám. XVIII -D-).

y parece subterránea, cubierta al interior con media bóveda de cañón, cuya parte aérea habría sido arrasada; a pesar de no haber localizado accesos o conductos para la circulación de agua, los investigadores la interpretaron como una fuente o cisterna, si bien parecería más bien la segunda posibilidad al localizarse exactamente el edificio en la desemboca- dura del arroyo, aunque no se descarta la otra posibilidad (Paris et alii, 1923, 99-100). La continuidad de las excavaciones en la zona permitió detectar la existencia en el paramento norte de la misma de un vano, totalmente decorado al exterior con pintura mural (figura $8 \mathrm{~B}$ ), interpretado como el dintel de acceso a la estancia, que no pudo ser excavado por- 
que se colmataba completamente de agua, a pesar de los diversos intentos en una campaña adicional realizada al efecto en 1921, concluyendo que sin bomba de succión no era posible hacerlo (Paris et alii, 1923, 100-101). Abandonando dicha tarea de vaciado de la estructura, se realizaron excavaciones en extensión, que permitieron concluir lo siguiente. En primer lugar, que en torno a la citada estructura se desarrollaban muros en disposición elíptica, tanto hacia un lado como hacia el otro, en una longitud difícil de verificar por ausencia de planos pero que al menos se extendía por unos $15 \mathrm{mts}$. lineales. $\mathrm{Y}$ en segundo término que dichos muros elípticos se relacionaban con un canal, visible en algunas de las fotografías, que se desarrollaba a lo largo de una amplia superficie (figura $8 \mathrm{C}$ y D). Hacia el oeste las estructuras iban quedando cada vez menos visibles, en parte por una inclinación (basculamiento) ya detectada, así como por el progresivo amalgamado de las mismas por su contacto con agua con mucha cal, que hacía la excavación muy compleja. La interpretación dada por Paris a este complejo monumento fue considerarlo bien un anfiteatro -cuyo eyrypus sería el canal- bien un posible ninfeo con pórticos, aportando paralelos en uno y otro sentido, aunque siempre con dudas (Paris et alii, 1923, 102-110).

Es evidente que sin nuevas actuaciones en el lugar no resulta posible decantarse al respecto, si bien resulta manifiesto que estas estructuras son monumentales y de gran porte -recordamos el empleo de sillería y el amplio aparato decorativo-, lo que de nuevo vuelve a incidir sobre la existencia de un auténtico suburbium en esta zona. La relación de este/os edificio/s con el agua es patente, como parece demostrar el canal excavado y la continua presencia y afloramiento hídrico. $\mathrm{Y}$ es evidente que se trata de un edificio con un programa decorativo cuidadoso, como se deduce de la ornamentación pictórica fitomorfa y recreando falsos mármoles en fachada.

Podríamos encontrarnos ante parte de un complejo termal, algo más que lógico si lo unimos a los datos que presentaremos en el siguiente epígrafe, en el cual se tratase de amplias habitaciones absidadas, a modo de exedras semicirculares, propias de este tipo de establecimientos balnearios, como encontramos en las grandes termas de Roma, desde época de Trajano en adelante (Yegül, 1995, 143, 149 o 156), a una escala, evidentemente, menor y adaptada al entorno provincial. O incluso parte de una gran palestra, como es el caso de la circular porticada de los baños occidentales de Gigthis en la Pro- consular, datada en la segunda mitad del s. II d.C., cuyos muros perimetrales curvilíneos precisamente se interconectan con una habitación dotada de umbral (Yegül, 1995, 221-222). Tampoco hay que descartar su interpretación como una fuente monumental, pues la presencia de nymphaea en relación directa con baños es una realidad bien constatada arqueológicamente (Yegül, 1995, 395). Ni considerar que el canal localizado, el cual se proyecta a lo largo de varias decenas de metros en dirección hacia el oeste, constituya quizás el final del specus del acueducto que debió traer agua a esta zona periurbana de la ciudad.

Por todo lo comentado, una conclusión importante que se deriva de los nuevos hallazgos realizados en la zona, conectando la gran potencialidad de la geofísica con los datos de las antiguas excavaciones de P. Paris es que toda esta zona situada al oeste de la desembocadura del arroyo de las Villas se corresponde con un ambiente periurbano, densamente ocupado en la Antigüedad, y que consideramos un auténtico suburbium marítimo, por integrarse el mismo entre la ciudad y la línea de costa.

Respecto a sus límites, el que resulta más evidente es el localizado al norte y al este, definido por el propio curso del arroyo. Es importante valorar que la conexión de este ambiente periurbano con la ciudad debía hacerse a través de algún puente que permitiese el paso hacia la otra orilla del arroyo y hacia la cercana Puerta de Gades, abriendo interesantes líneas de investigación para el futuro en este sentido; otra de ellas es la conexión con las estructuras excavadas en el año 1999 al oeste del barrio industrial, que quizás podrían esconder tras de sí una torre de la muralla o el bastión de una puerta, como ha sido sugerido (Alarcón, 2007, 231), lo que permitiría un tránsito en dirección este-oeste entre el barrio industrial y esta aglomeración periurbana; y la tercera línea de investigación a desarrollar es que este paleocauce del arroyo debió disponer de muros de contención de sus orillas, pues la entidad de las estructuras a ambos lados del río no permite entender este curso de agua de otra manera, al menos en su tramo final, entre la Puerta de Gades y el mar.

El límite sur es evidente, coincidiendo con la propia línea de costa, difícil de trazar actualmente debido a la notable erosión de la parte meridional del yacimiento y a las playas de neo-formación que colmatan todo este sector ${ }^{7}$ (Alonso et alii, 2007),

7 Han sido de gran utilidad las fructíferas conversaciones 
lo que permite entender el brusco cambio de rasante entre las estructuras arqueológicas más meridionales del yacimiento y la playa actual. Al menos las estructuras se proyectaban hasta el actual inicio de la playa, como demuestran los caementa, aparentemente en posición primaria, aunque algo basculados, ya citados (figura 6).

La delimitación occidental nos parece, por el momento, la más compleja, ya que tradicionalmente se hace coincidir el inicio de la necrópolis occidental con el entorno suroccidental de la Puerta de Gades, utilizando como argumento los trabajos de inicios de siglo del jesuita belga Furgus, que excavó varias tumbas en esta zona (1907 y 1908). Esta propuesta parece mantenerse en los últimos trabajos realizados sobre el mundo funerario en la ciudad, interpretando estructuras en superficie en la zona con tumbas altoimperiales -unas siete unidades funerarias- (García Jiménez, 2008, 106-107, lámina 2; 61-62; Muñoz, García y Prados, 2009, 61-63). Pensamos que a la luz de todos estos hallazgos conviene realizar la limpieza de las estructuras y un estudio micro-espacial en la zona antes de decantarse al respecto, algo no posible en la actualidad, conscientes de la existencia de estas importantes estructuras urbanas entre el cauce del arroyo y el inicio de la necrópolis occidental. Una atenta lectura de los citados trabajos del jesuita belga -muy similares entre sí- confirma que la localización de la que hoy llamamos necrópolis occidental se sitúa "sur une petite colline couverte d'une couche de sable épaisse parfois de 2 à 3 mètres, ne renfermait que des urnes cinéraires", habiendo excavado una treintena de cremaciones (Furgus, 1907, 11); La "Necrópolis de Poniente, algo más distante de la ciudad que la primera, está situada sobre una ligera elevación o colina... las excavaciones practicadas repetidas veces en aquel sitio han dado a conocer que una extensa muralla separaba la necrópolis de la vecina playa, y cimientos puestos al descubierto, junto a la misma muralla, revelan la existencia en aquel lugar de un pequeño pero macizo edificio" (Furgus, 1908, 210). De dichas descripciones podemos inferir que la necrópolis occidental, según el autor, arranca en la ladera de la duna consolidada ${ }^{8}$,

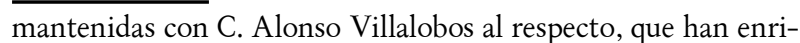
quecido sustancialmente la versión final de este texto.

8 A este respecto es de gran interés una fotografía de la necrópolis occidental recientemente publicada, conservada en el Archivo General de Andalucía (AA.VV., 2009, 134, n ${ }^{\circ} 74$ ), en la que se advierte la entidad de las estructuras murarias ex- y no desde la plataforma llana situada al suroeste de la Puerta de Gades; además de la existencia en el propio entorno funerario de estructuras de notable entidad, junto a la playa, que quizás no tengan que ver nada con la necrópolis. Por último, indicar que los ajuares que presenta el autor (Furgus, 1907, 1215 , figs. I-III) -sigilatas clásicas, quizás algún plato de ARSW A, cerámicas comunes y ungüentariosasí como las monedas que cita permiten plantear una cronología para ella entre Augusto y el s. II d.C.

Aunque sea por tanto complejo valorar con precisión las dimensiones de esta área suburbana baelonense, pensamos que una estimación en torno a una hectárea es la propuesta más viable en la actualidad, con la duda de su cierre exacto por el área occidental. Esta dinámica según la cual las necrópolis baelonenses no arrancan directamente desde el área de muralla también se ha constatado en el lienzo oriental, en torno al cual existe un amplio sector de vertedero de residuos sólidos, excavado y bien documentado en los últimos años (Bernal et alii, 2011), que también proyecta el inicio del cementerio altoimperial oriental a varias decenas de metros al este de la Puerta de Carteia.

En segundo término, indicar que en principio se descarta la posibilidad de que nos encontremos ante una villa periurbana de grandes dimensiones ya que, como veremos en el siguiente apartado, la notable entidad de las estructuras balnearias aparecidas hace pensar más en edificios de carácter público que en una residencia privada. Y tampoco conocemos otros ejemplos de este tipo de poblamiento en ámbito periurbano en el área objeto de estudio, ya que las escasas villae en la ensenada de Bolonia, como la de La Torre, con ocupación alto y bajoimperial, se sitúan en ámbitos bastante alejados de la ciudad (Arévalo, Bernal y Lorenzo, 2007, 42-45, fig. 5). En el ámbito del Fretum Gaditanum las villae periurbanas se sitúan alejadas del pomerium, al menos en los ejemplos conocidos, como sucede con la de los Cuarteles de Varela en Cádiz, aún inédita, y en otras ciudades cercanas como Carteia la notable alteración del área inmediata a la muralla no permite aportar muchos datos, aunque es cierto que ni siquiera hay indicios de este tipo de patrón de asentamiento villático periurbano (Roldán et alii, 2006).

cavadas en la zona por P. Paris y G. Bonsor, confirmando los hallazgos de J. Furgus en las inmediaciones. 

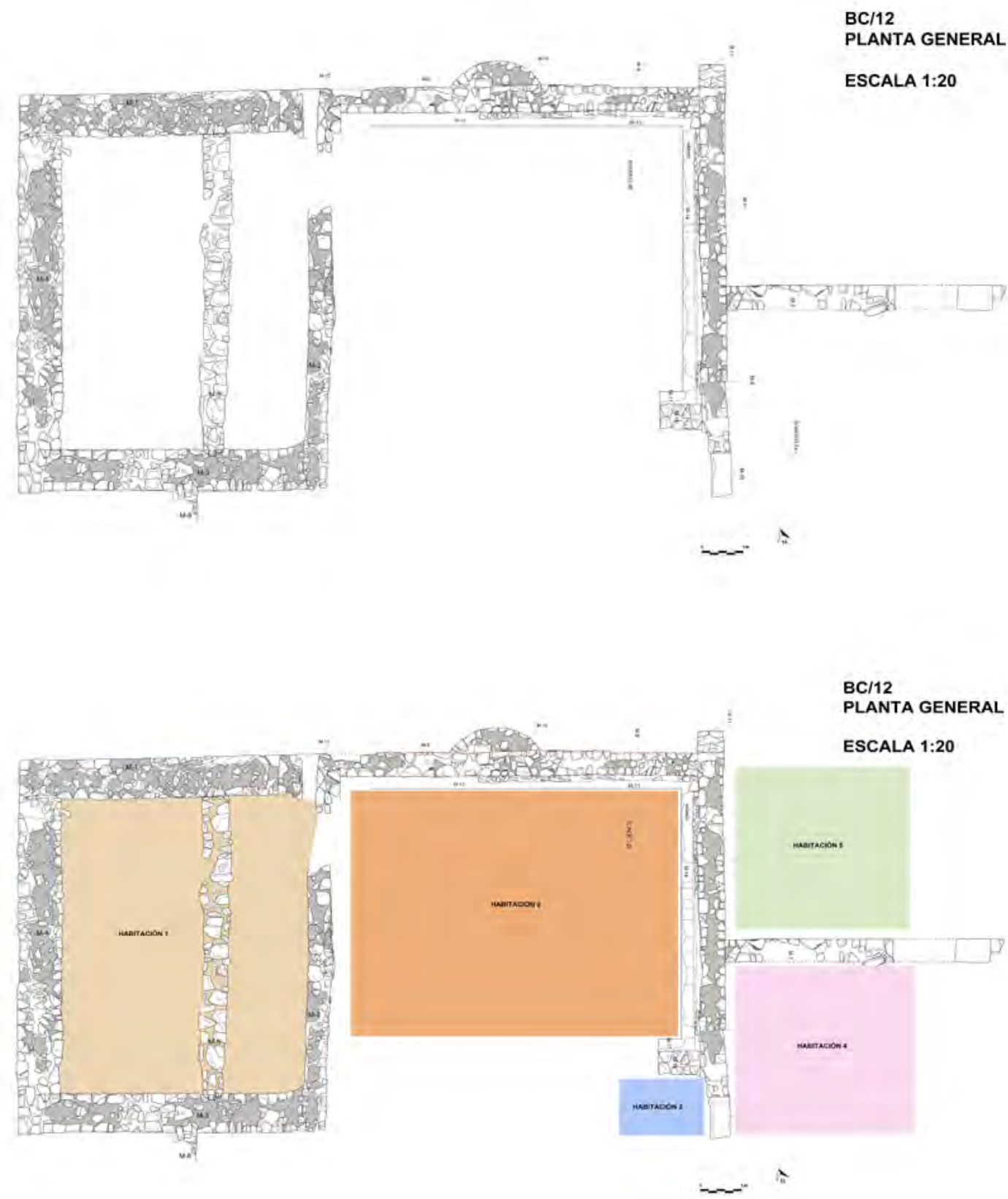

Figura 9. Planimetría general de las estructuras (H-1 a H-5) del edificio termal suburbano de Baelo Claudia, con la numeración de las unidades murarias y los cuatro sondeos arqueológicos realizados (22 a 25$)$.

Este es el primer caso constatado en Baelo Claudia de un auténtico suburbium, y conscientes de la dinámica poblacional en otras zonas podría ser el único, al menos de esta entidad. Aunque indicios diversos permiten valorar que al sur de la necrópolis oriental existen algunas estructuras de entidad que quizás haya que relacionar con un patrón poblacional similar, aunque de menor entidad y extensión. Se trata éste de un tipo de poblamiento que no ha sido objeto de estudio intensivo en nuestras ciudades hispanorromanas hasta fechas muy recientes (Vaquerizo, 2010, ed.), monografía en la cual se analizan 


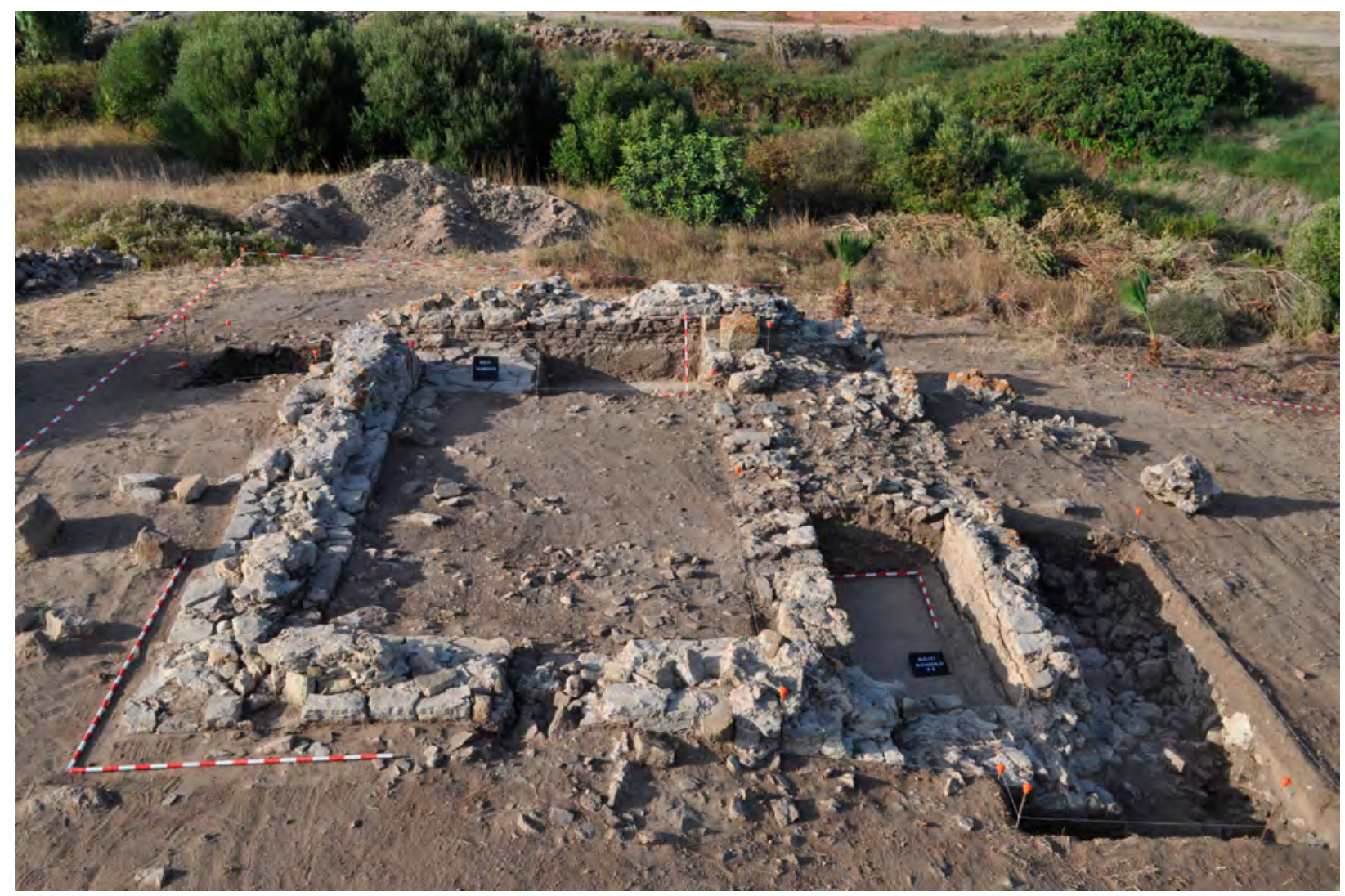

Figura 10. Vista general desde el sur de la habitación excavada en julio de 2011 (Sondeos 22 y 23).

algunos casos singulares como los de Complutum, Barcino, Tarraco, Segobriga, Carthago Nova, Baetulo o Augusta Emerita, analizando en Baetica la problemática de Colonia Patricia (Murillo y Vaquerizo, 2010) y Onoba Aestuaria (Campos, 2010). En el ámbito litoral más cercano a nosotros el único ejemplo parangonable es el del área suburbial de Carteia, con dos ambientes: Villa Victoria, de carácter industrial y cuya lejanía respecto a la ciudad -más de un kilómetro- hace pensar más en un pequeño vicus alfarero y pesquero-conservero, con sus instalaciones portuarias independientes y su propia necrópolis (Bernal et alii, 2004; Blánquez et alii, 2005), y el barrio suburbano pesqueroconservero que discurriría inmediatamente al sur de las murallas de la ciudad, excavado parcialmente por Santa Olalla y Woods y recientemente objeto de actuación arqueológica (Expósito y García, 2012, 301, fig.1); y evidentemente Gades, con un patrón de ocupación suburbial disperso y también centrado en actividades pesquero-conserveras y alfareras, que alternan con las funerarias (Bernal y Lara, 2012).
Sobre todas estas cuestiones habrá que profundizar en el futuro, si bien se abre una nueva línea de investigación para esta ciudad marítima, que no había sido abordada hasta la fecha por la ausencia de evidencias.

Las termas suburbanas de $B$ AELO CLAUdia: PRIMEROS DATOS.

Tras la ejecución de la ya citada prospección geofísica, se decidió realizar una serie de sondeos $y$ transectos de comprobación en torno a los paramentos emergentes del edificio situado sobre la cota más alta del promontorio, a través de una actividad arqueológica que se ha acometido durante los años 2011 y $2012^{9}$, cuyos primeros datos presentamos en

9 Autorizada por la Dirección General de Bienes Culturales de la Consejería de Cultura de la Junta de Andalucía y dirigida por uno de los miembros del equipo (J.J.D.), la primera fase de la misma se desarrolló en julio de 2011, en el ámbito del XII Curso Internacional de Arqueología Clásica en Baelo Claudia, prolongándose hasta mediados de agosto; y la segunda fase entre el 9 y el 27 de julio del año 2012. 


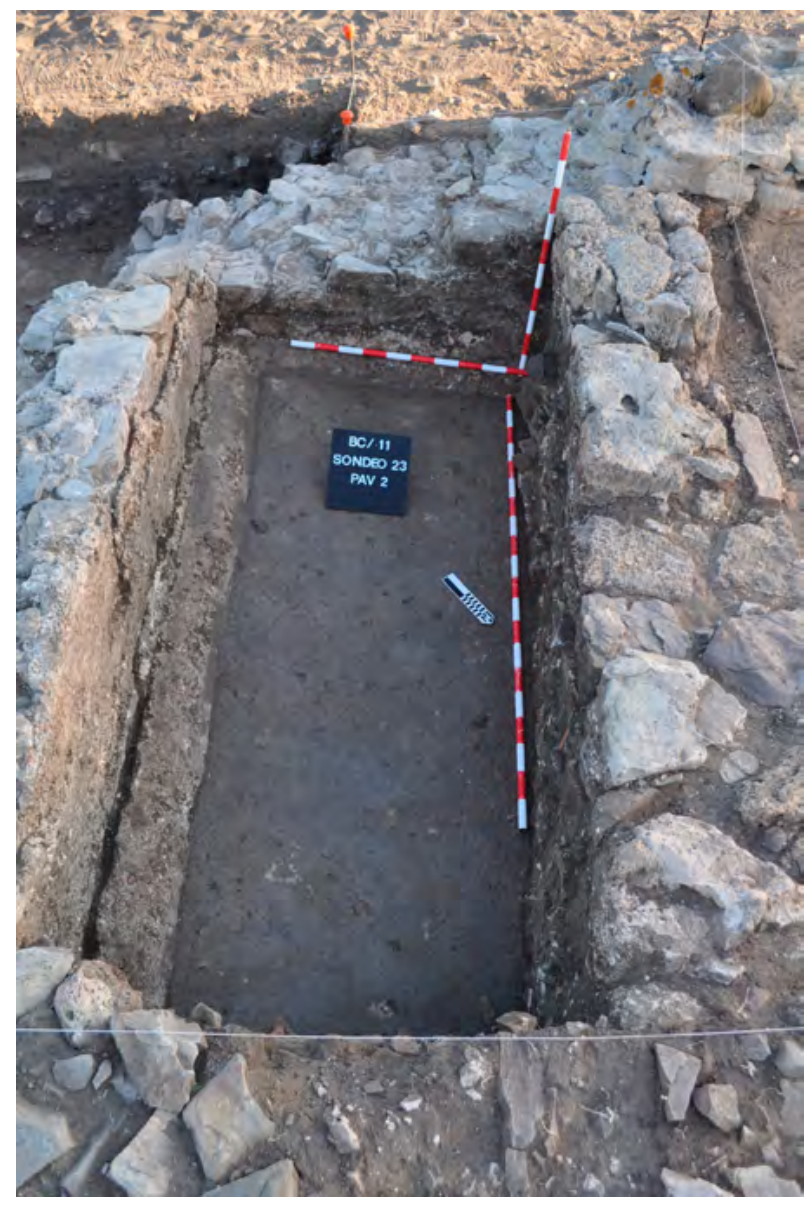

Figura 11. Detalle de los paramentos interiores sur y este de la habitación $\mathrm{H}-1$, totalmente revestidos de opus signinum (Sondeo 23).

estas páginas, con una planimetría esquemática de las estructuras identificadas (figura 9) ${ }^{10}$.

En primer lugar se pudo intervenir sobre la habitación cuyos paramentos eran emergentes, y que es la que propiciaba la intervención, habiendo podido aclarar su planta por completo, mediante una limpieza superficial y la excavación alterna en su cuadrante NO (Sondeo 22) y SE (Sondeo 23), como se aprecia en la figura 10 . Se pudo confirmar la totalidad de su planimetría, tratándose de una habitación completamente rectangular, que denominamos $\mathrm{H}-1$, de unos $47 \mathrm{mts}$ de superficie interior ( 8,4 en dirección norte-sur por 5,6 este-oeste), descartando que el muro de ostionera interno, que dividía la habita-

10 Son los denominados Sondeos 22, 23, 24 y 25 , cuya problemática específica y de detalle dejamos para posteriores trabajos, así como la nomenclatura específica a las UU.EE. y UU.CC, que simplificamos para esta primera presentación. ción en dos compartimentos, fuese coetáneo. En un primer momento se había especulado con la posibilidad de que dicho muro pudo generar la caja de una escalera para acceder a la parte alta (parte oriental, de mucha menor anchura) del edificio. Sin embargo, tras los trabajos arqueológicos de campo, se ha comprobado que se correspondía con una refectio contemporánea, a la cual también se asociaba el gran pavimento de losas de jabaluna (piedra local), asociadas a la reutilización del edificio con posibles fines militares, como se deducía del hallazgo de munición en los niveles de abandono. El segundo aspecto de interés es que el interior del mismo estaba totalmente revestido de opus signinum, como se confirmó en los cuatro muros perimetrales interiores, en cuya parte interior se documentaba un amplio cuarto de bocel que recorría horizontalmente la totalidad de los extremos perimetrales de su planta, para evitar filtraciones (figura 11). Es evidente que la $\mathrm{H}-1$ se relaciona con el tránsito y contención de agua, cuyos puntos de admisión y desagüe no han sido localizados al haberse excavado la zona parcialmente, pero que quizás se correspondan con una discontinuidad detectada en su paramento meridional o M-3, y en la conexión con la H-2, por el este. Las amplias dimensiones de sus muros perimetrales, aproximadamente en torno a $1 \mathrm{~m}$. de anchura, a excepción del oriental (M-2), de $50 \mathrm{cms}$. de espesor, permitían plantear que podríamos encontrarnos ante una cisterna o receptáculo hídrico de cierto porte, menor que la gran cisterna de la ciudad (aproximadamente una cuarta parte de su capacidad), situada al norte del área intramuros y con una superficie de unos 180 $\mathrm{m}^{2}(30 \times 6$, con un lateral absidado al sur; Sillières, 1997, 145), pero de mayores dimensiones que las restantes conocidas (Alarcón, 2002; Bernal et alii, 2011, 67-73). Dos aspectos resultaban un poco anómalos en relación a esta interpretación: de una parte su carácter aéreo, al menos parcialmente, y de otra el menor espesor de su compartimentación oriental, lo que unido a otras estructuras visibles en superficie hacia el curso del arroyo permitían plantear la conexión de la misma con otros edificios hacia el este.

La excavación al exterior de la $\mathrm{H}-1$ en su ángulo NO (ampliación del Sondeo 22 hacia occidente) permitió documentar su amplia potencia estratigráfica exterior, superior al metro de altura conservada, documentando su zapata constructiva, aparecida a un metro aproximado de profundidad bajo la cota actual y caracterizada por una rebaba de argamasa (figura 12). 


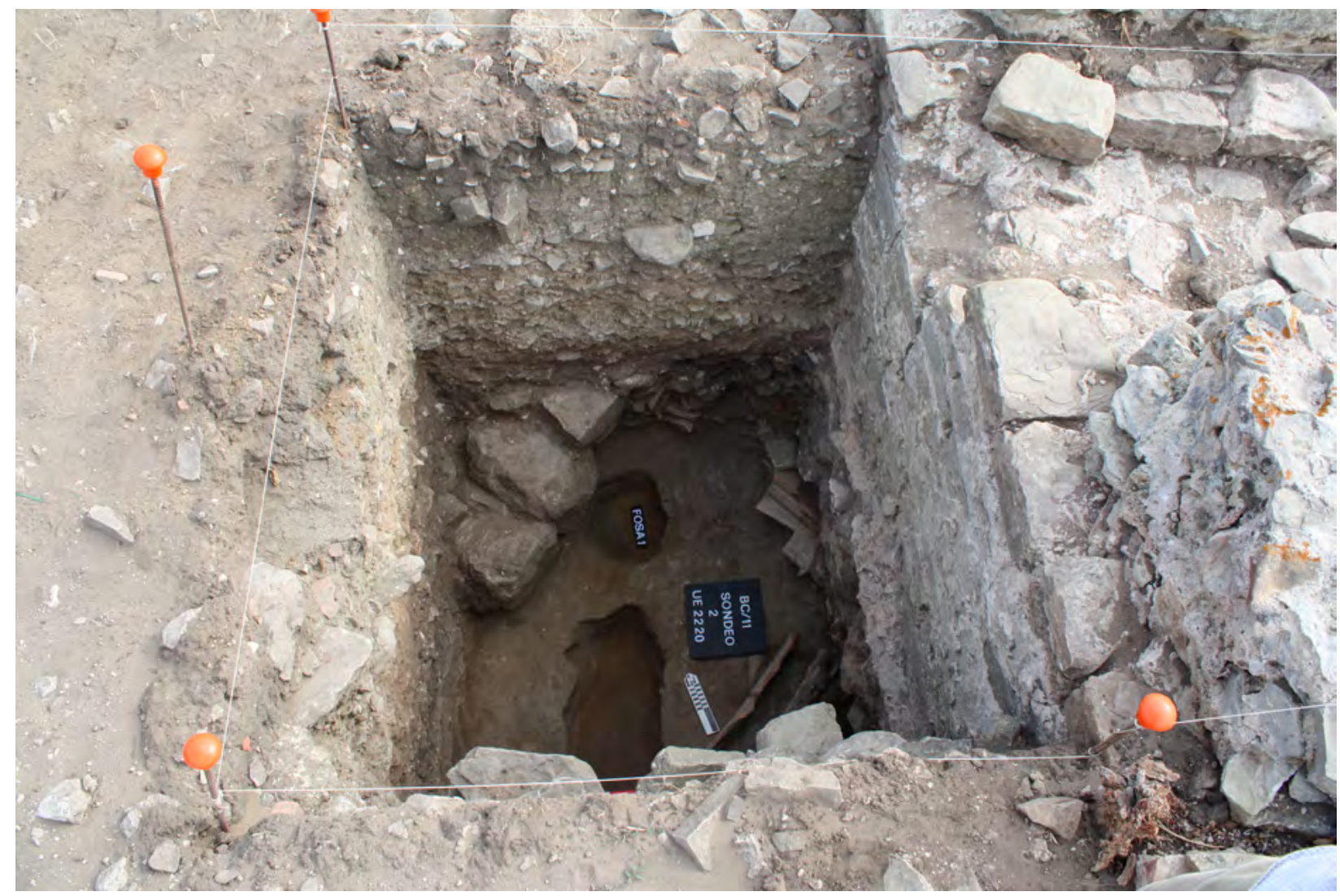

Figura 12. Vista desde el sur de la ampliación occidental del Sondeo 22, con la zapata de la H-1 y las estructuras infrayacentes.

Especialmente significativa fue la posibilidad de haber podido fechar el momento de construcción de esta estructura, gracias a la cata estratigráfica en profundidad acometida al exterior del M-4. La cimentación de la $\mathrm{H}-1$ parte a varios estratos precedentes, los cuales aportan un terminus post quem para su erección. El más profundo de los afectados o U.E. 2218 presenta una datación en época augustea avanzada o tardoagustea, según se desprende de la presencia de TSI de la forma Conspectus 7 -AA.VV, 2002, 64- (figura 13, 1), junto a ánforas de época tardorrepublicana como una posible Ovoide del Valle del Guadalquivir (figura 13, 2), el borde y quizás la carena de una Dr. 1C, ambas con pastas de tipo El Rinconcillo (figura 13, 4 y 5 ) junto a un ánfora de tipo indeterminado (figura 13, 3) documentada en abundancia en la ciudad en los niveles republicanos (sondeos de Domergue, 1973), así como una pared de un ánfora ebusitana (figura $13,6)$, algunas de ellas quizás residuales. Asimismo, sobre él se situaba la U.E. 2217, cuya datación situamos en época posiblemente tardo-neroniana (60/70), guiados por la convivencia de TSG (figura
13, 9-11) ya con algunas formas de hispánica del valle del Najerilla (figura 13, 12-13), con algunas pervivencias de sigilatas itálicas (figura 13,8), en un contexto cerámico con escasas ánforas y multitud de cerámicas comunes (figura 13, 14-17), momentos en los cuales aún no habían hecho su aparición las cerámicas africanas (ni finas ni africanas de cocina). Estos niveles anteriores (especialmente la U.E. 2218) depararon muchos restos de pintura mural, haciendo pensar quizás en un uso tampoco industrial en estos momentos.

Sobre ellos se localizan los estratos que se asocian a la construcción propiamente dicha de la $\mathrm{H}-1$, tanto el nivel de uso primigenio exterior de la habitación tras la construcción, horizontalizando dicho espacio (U.E. 2211; pues su preparación o U.E. 2216 no aportó materiales datantes), como un relleno que creó una elevación posterior inmediata a su erección ${ }^{11}$ (U.E. 2207). En ambos casos las dataciones tienden

11 Es interesante el hallazgo de un fragmento de una esponja de mar en este estrato, que debemos asociar posiblemente a las actividades higiénicas vinculadas al edificio balneario. 

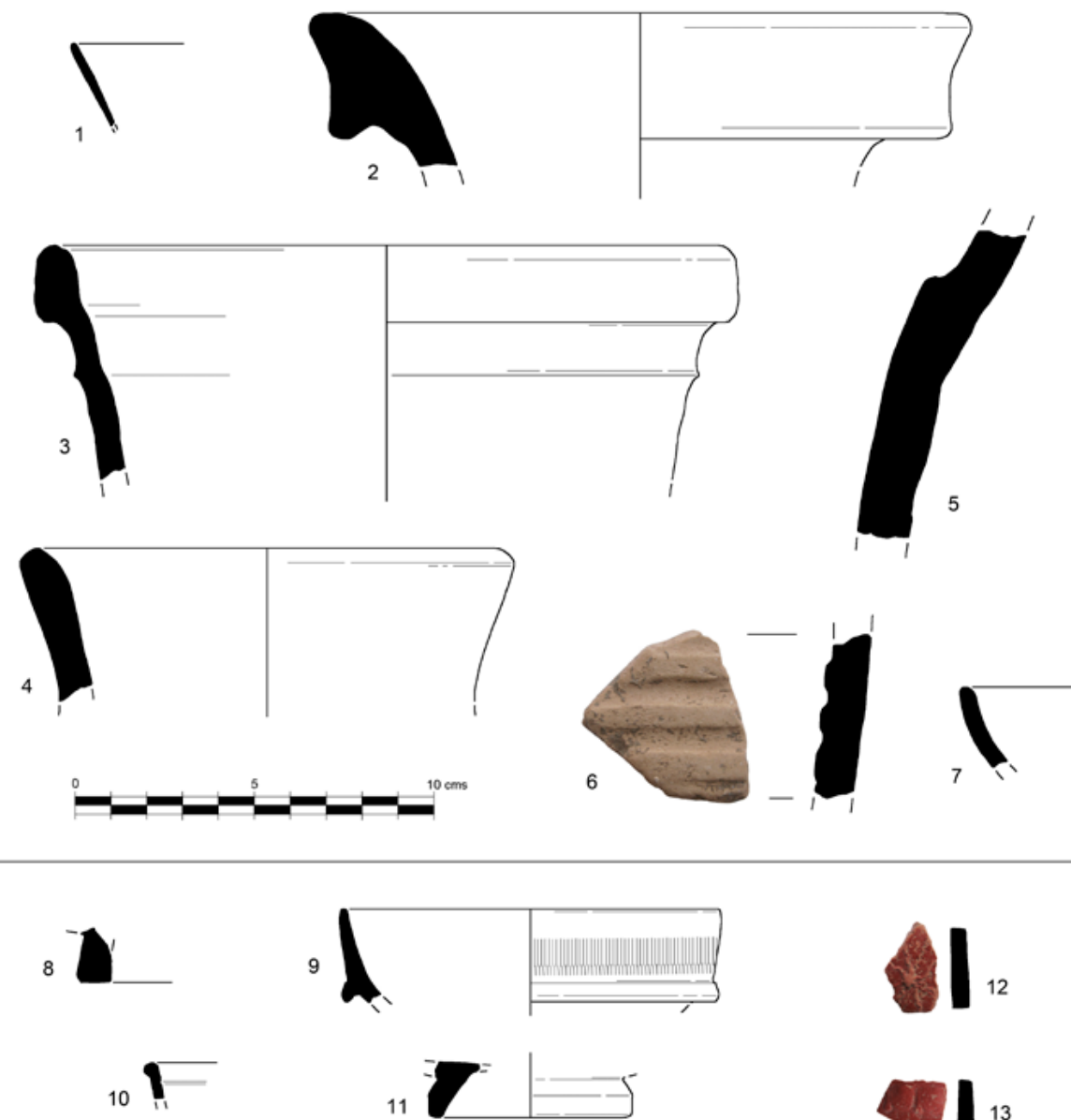

10

11
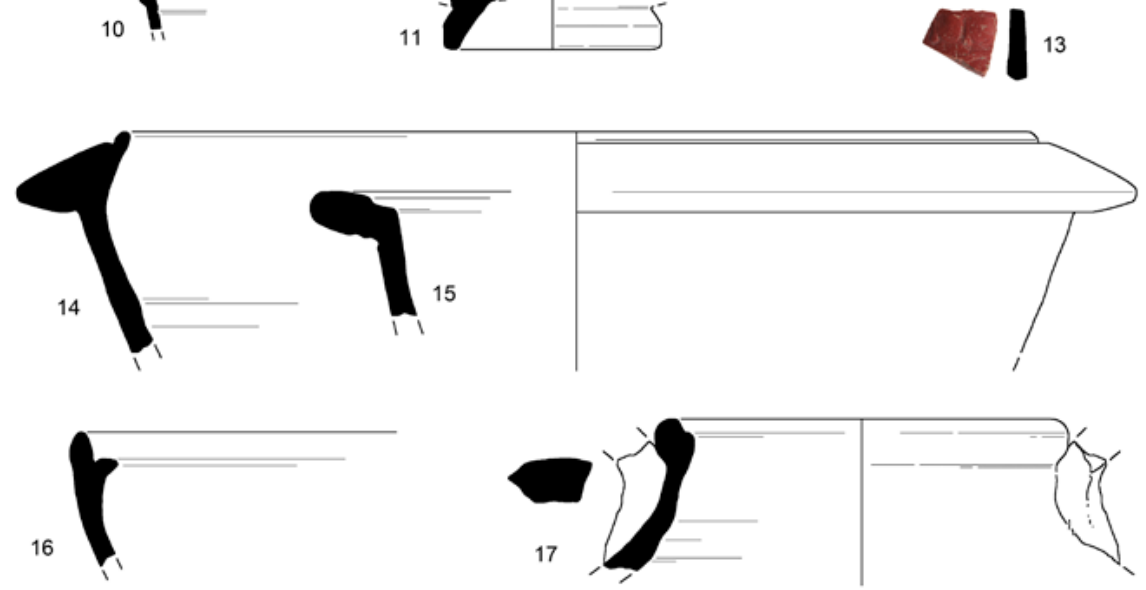

Figura 13. Selección de los contextos cerámicos de las fases previas amortizadas por la construcción de la H-1 (UU.EE. 2218 y 2217). 1.- Borde de Conspectus 7 en TSI (BC/11/2218/1); 2.- Borde de posible ánfora ovoide (BC/11/2218/2); 3.- Borde de ánfora tardorrepublicana indeterminada (BC/11/2218/3), emparentada con las Dr. 21/22; 4.- Borde de posible ánfora del tipo Dr. 1 C (BC/11/2218/4); 5.- Carena de ánfora republicana (BC/11/2218/5); 6.- Pared de ánfora ebusitana (BC/11/2218/6); 7.- Borde de cuenco en común a torno (BC/11/2218/7); 8.- Fondo de pátera en TSI (BC/11/2217/1); 9.- Borde de Drag. 24/25 en TSG (BC/11/2217/2); 10.- Borde de Drag. 27 a en TSG (BC/11/2217/3); 11.- Fondo de copa Drag. 27 en TSG (BC/11/2217/4); 12.- Pared decorada de la forma 30 en TSH, con cruces de San Andrés (BC/11/2217/5); 13.- Pared decorada de Hispánica 30 (BC/11/2217/6); 14.- Olla de común a torno (BC/11/2217/7); 15.- Mortero en común a torno (BC/11/2217/8); 16.- Cazuela en común a torno (BC/11/2217/9); 17.- Olla en común a torno (BC/11/2117/10). 


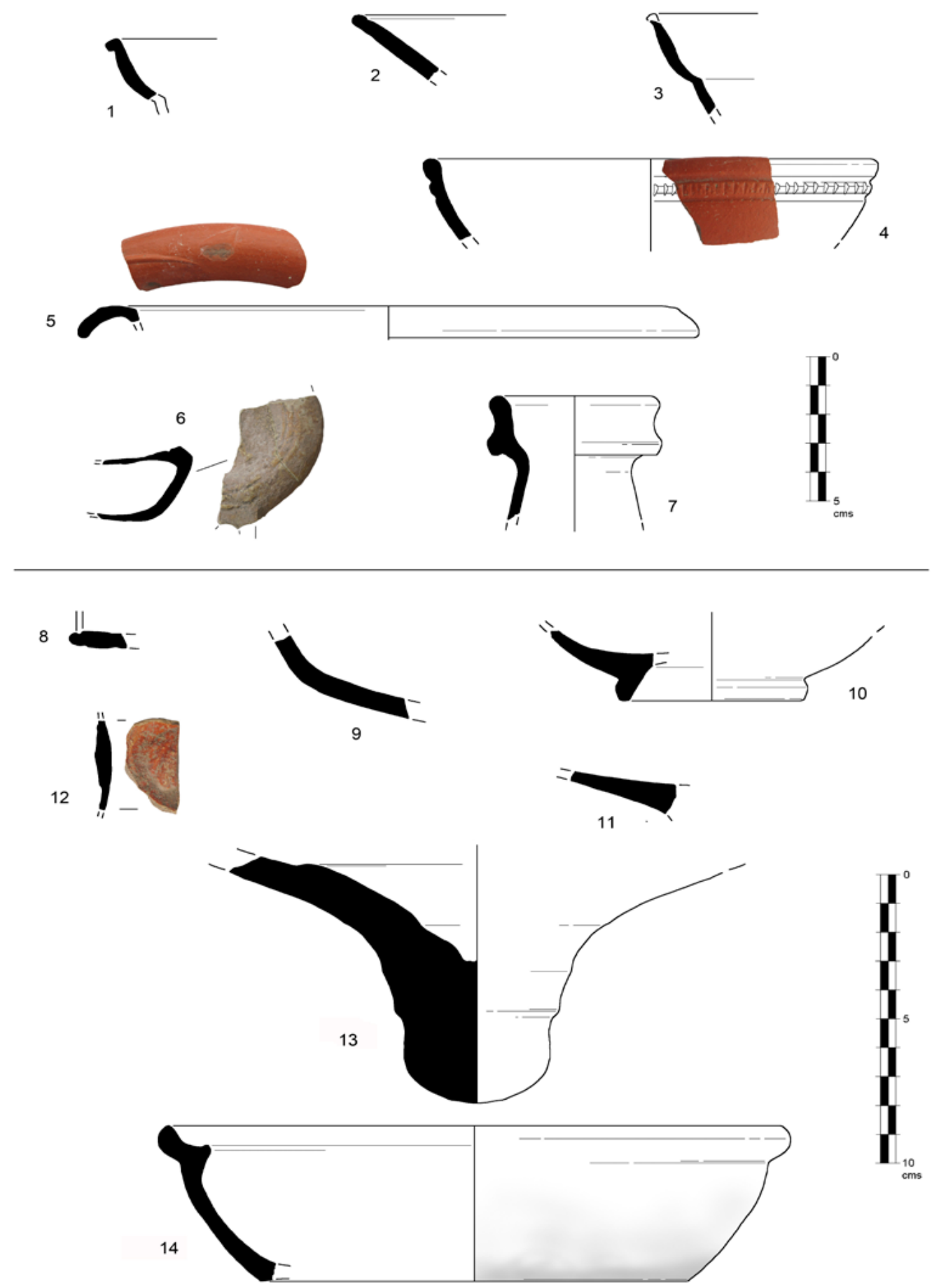

Figura 14.- Selección de los contextos cerámicos asociados a la construcción de la H-1 (UU.EE. 2207 y 2211). 1.- Borde de Drag. 18 en TSG (BC/11/2207/1); 2.- Borde de forma 15/17 en TSH (BC/11/2207/2); 3.- Pared de forma 27 en TSH (BC/11/2207/3); 4.- Borde de Hayes 9 en ARSW A (BC/11/2207/4); 5.- Borde de Hayes 3C en ARSW A (BC/11/2207/5); 6.- Rostrum, orla y disco de lucerna del tipo Dr. 20 (BC/11/2207/6); 7.- Boca de jarra en común a torno (BC/11/2207/7); 8.- Borde de Hayes 6 en ARSW A (BC/11/2211/1); 9.- Pared de Hayes 9 en ARSW A (BC/11/2211/2); 10.- Fondo de 24/25 o 27 en TSH (BC/11/2211/3); 11.- Pared de 15/17 en TSH (BC/11/2211/4); 12.Disco decorado de lucerna altoimperial (BC/11/2211/5); 13.- Pivote de ánfora africana (BC/11/2211/7); 14.- Borde de cazuela en común a torno $(\mathrm{BC} / 11 / 2211 / 6)$. 
a situar la construcción de la cisterna en la primera mitad del s. II d.C. En la U.E. 2211 encontramos la convivencia de TSH -como una copa de la forma 24/25 o 27 o parte de una pátera de hispánica 17 (figura 14, 10 y 11)- junto a varias formas de ARSW A, concretamente el borde de una Hayes 6, de variante indeterminada (figura 14, 8), fechada habitualmente entre finales del s. I y finales del s. II (Hayes, 1972, 31); y una pared en $A^{1}$ de una Hayes 9 (figura 14, 9), posiblemente de las variantes precoces y datable por ello entre el 100 y el 160 d.C. (Hayes, 1972, 37), junto a una lucerna de disco (figura 14,12), el borde de una cazuela de borde bífido en común (figura 14, 14) y el pivote de un ánfora africana (figura 14,13), todo ello coherente con unas fechas de la segunda centuria. La convivencia en la U.E. 2207 de sigilatas clásicas con cerámicas africanas es, de nuevo, patente: como el borde de una Drag. 18 en TSG (figura 14, 1), una Hispánica 15/17 evolucionada (figura 14, 2) y una forma 27 con el lóbulo superior muy desarrollado (figura 14, 3), junto a una Hayes 9 A en ARSW $\mathrm{A}^{1}$ (figura 14, 4), también de la variante $\mathrm{A}(100-160$ aprox.) y al borde con una hoja de agua de una $\mathrm{Ha}-$ yes $3 \mathrm{~B}$-sin acanaladura pero decorada- (figura 14, 5), datada entre el 75-150 (Hayes, 1972, 25), además de una lucerna del tipo Dr. 20 - Deneauve VII subtipo 1 , variante A (figura 14, 6), propia del s. II (Bonifay, 2004, 322), y el cuello de una jarra en común a torno (figura 14,7). Por todo ello consideramos que la cisterna H-1 se debió construir posiblemente en época de Trajano o Adriano, pues algunas formas de sigilatas africanas no existían previamente al cambio de siglo (como la Hayes 9), al tiempo que buena parte de ellas (Hayes 3B y 9) son sustituidas por variantes más tardías a partir de entonces. Es posible que dentro de este intervalo la erección se centrase en los años del primer cuarto, dada la elevada presencia aún de sigilatas gálicas, el carácter arcaizante de las formas de TSH (como la moldura interior aún visible en la forma 15/17 o la escasa inclinación exterior del lóbulo superior de la copa 27) y por la ausencia de formas propias del repertorio de mediados del s. II en ARSW A (como la Hayes 14), aunque por prudencia preferimos, a esperas de ulteriores estudios, proponer una datación entre el 100 y el 150 d.C.

El periodo de actividad de esta estructura se mantiene hasta momentos avanzados del s. V d.C., como confirma la presencia de un contexto cerámico muy homogéneo asociado a los diversos estratos de colmatación interior de la $\mathrm{H}-1$, detectados en ambos sondeos interiores, y que coincide con los datos obtenidos en otros ambientes intervenidos en el año 2012 (figuras 19 y 20), por lo que consideramos ésta como la fecha de definitivo abandono de este edificio.

La ampliación occidental del Sondeo 22 permitió, asimismo, confirmar que previamente a la construcción de este edificio existían sobre este cerro, generado y sobre-elevado de manera artificial durante el Alto Imperio como resultado precisamente de estos programas edilicios, otras fases precedentes, caracterizadas por estructuras que seguían una orientación diversa y que además se asentaban sobre niveles de dunas fósiles. La intervención sobre estas fases precedentes fue epidérmica, sin llegar a agotar la estratigrafía, a pesar de lo cual se pudo confirmar la existencia en los estratos más profundos de restos de ictiofauna de bastante entidad, asociados a fosas y canalizaciones con ímbrices sobre la arena. Es un contexto muy similar a los detectados en el año 2001 bajo el Conjunto Industrial VI citados más arriba, que además, por la presencia de barnices negros, permiten prolongar su datación hasta momentos pre-augusteos. Esta constatación es de gran importancia en relación a los objetivos generales del proyecto, ya que confirma que previamente a la construcción de estas edificaciones el uso de la zona era diverso, vinculado -al menos en la parte excavada- con la explotación de recursos marinos ${ }^{12}$. Indicar, por último, que estas estructuras documentadas previamente a la construcción de la $\mathrm{H}-1$ confirman que la entidad de las fases constructivas precedentes es incluso más consistente de lo intuido por los resultados de las prospecciones geofísicas, ya que en esta zona únicamente se habían identificado algunos estratos de derrumbe al oeste del edificio (figuras $4 \mathrm{C}$ y $4 \mathrm{D}$ ), con resultados negativos en la zona intervenida.

Durante la intervención del año 2011 también se procedió a la limpieza superficial de la zona más oriental, en la cual aparecieron los restos de una segunda habitación o $\mathrm{H}-2$, la cual se excavó parcialmente (figura 15), pudiendo identificar en ella la presencia de sendos contrafuertes exteriores, uno rectangular y otro semicircular, así como la existencia de un revestimiento interior de hormigón

12 Recordamos que en las fases augusteas y del s. I intermedias, representadas por la U.E. 2217 y por otros estratos, el hallazgo de abundante pintura mural de varios colores hace pensar en una funcionalidad ajena a lo haliéutico (ivinculada también a un uso termal, al cual se asociaría el fragmento de pila realizado en ladrillos recuperado en la U.E. 2219?). 


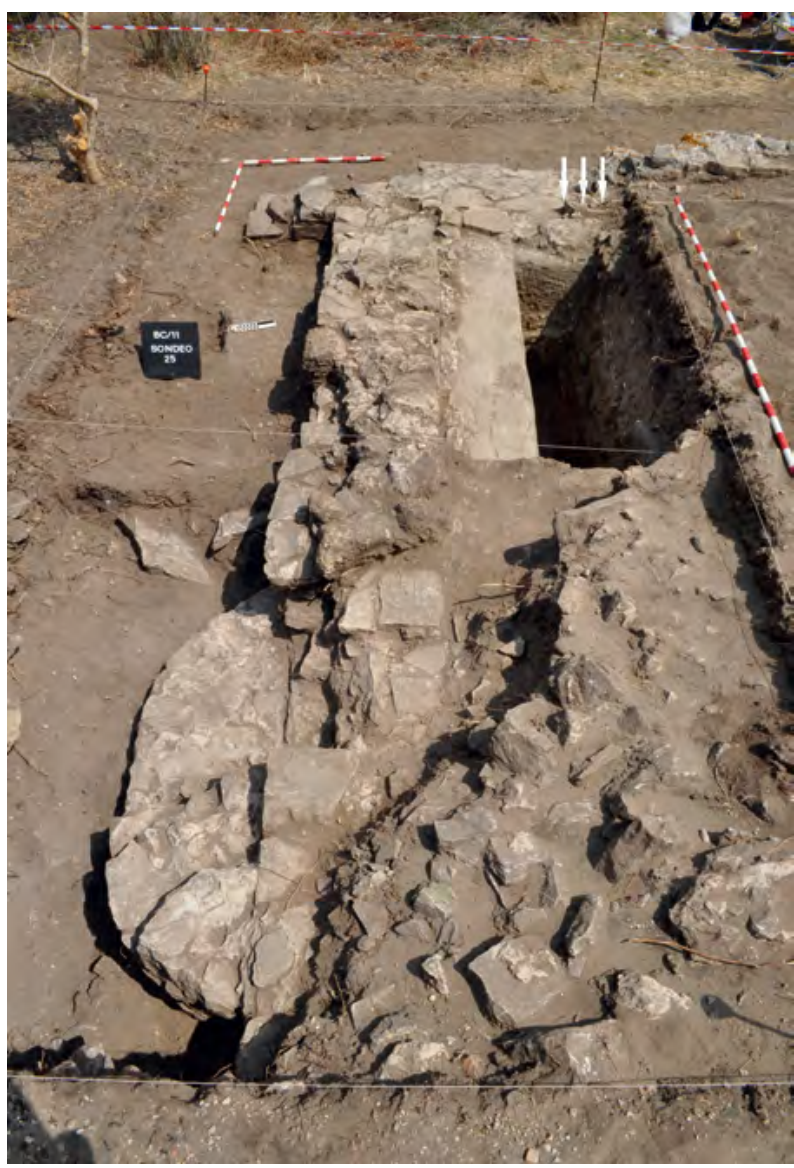

Figura 15.- Vista desde el oeste de las estructuras de la H-2 localizadas en el Sondeo 25, con indicación de las placas de revestimiento marmóreo (flecha).

hidráulico, desde la parte alta a la baja, a modo de cubeta y/o piscina.

El contrafuerte semicircular exterior, posible refrendo de una hornacina que tuviese la habitación al interior, era un elemento clave para la interpretación del edificio como un complejo termal, ya que en el alveus occidental del frigidarium de las termas urbanas de Baelo, de planta rectangular, existe uno de idéntica morfología, aunque de menores dimensiones (1,2 de diámetro, frente al nuestro que es de $2 \mathrm{mts}$.). Otros elementos parecían apuntar también a que nos encontrábamos ante un complejo balneario, como sucedía con un pilar de ladrillo revestido con argamasa exterior, a modo de pila de un hipocausto, aparecido en un nivel de relleno (U.E. 2219) y por ello en posición secundaria; o la aparición de teselas en varios estratos (como en la U.E. 2207, de vidrio), elementos musivarios tremendamente singulares en la edilicia baelonen- se; una placa de mármol de grandes dimensiones, fragmentada, destinada a ser colocada en el suelo (U.E. 2504, derrumbe de la H-2), muy similar en factura y dimensiones a la existente in situ sobre el pavimento de la piscina semicircular del frigidarium de las termas baelonenses. Algunos fragmentos de material constructivo latericio, tanto ladrillos con escotaduras (como sucede con un ejemplar reutilizado en una reforma detectada en el ángulo noroeste en la $\mathrm{H}-2$ ) como testae con rebordes retranqueados, destinados a la generación de dobles paredes (diversos contextos) eran otros indicios de entidad, pues su tipología se vincula con claridad a complejos balnearios, tanto en Baetica como en otros lugares del Imperio (Roldán, 2008, 754-760, fig. 5). Asimismo, la documentación en la parte superior de la $\mathrm{H}-2$ de un embellecimiento a base de pequeñas placas marmóreas en disposición vertical (figura 15, flecha), prácticamente idénticas a las aún situadas in situ en las paredes del frigidarium de las termas de Bolonia, constituía otro elemento adicional al respecto.

En julio de 2012 se planteó la continuidad de la actividad arqueológica para intentar confirmar que nos encontrábamos ante unas termas propiamente dichas, para lo cual se decidió ultimar los sondeos iniciados la anualidad precedente tanto en la zona septentrional de la H-2 (Sondeo 25) como a lo largo de su perímetro oriental (Sondeo 24), de manera que fuese posible determinar las dimensiones totales de dicha piscina. El resultado ha sido satisfactorio, ya que se han podido confirmar los vértices $\mathrm{NO}$ y SE de la habitación, lo que unido al ya existente (NE) permiten plantear una superficie aproximada de unos $52 \mathrm{~m}^{2}$ (6,5 mts. N-S por $\left.8 \mathrm{E}-\mathrm{O}\right)$, suponiendo que la misma fuese totalmente rectangular y no contase con un retranqueo y/o con escaleras de acceso hacia el sur/suroeste, como es probable (figura 16). Se ha realizado un sondeo estratigráfico en su interior, para poder determinar así su sistema constructivo y características edilicias, habiendo confirmado que la misma dispone de una profundidad de 1,3 mts., por lo que su volumetría total sería de más de $65 \mathrm{~m}^{3}$, lo que da una idea de su entidad (figura 17).

Se han podido determinar algunos detalles edilicios significativos, como sucede con el revestimiento de placas marmóreas que tuvo la piscina en una primera fase, las cuales fueron casi totalmente expoliadas en la Antigüedad. De ellas quedan sobre el suelo sus huellas, al menos en la zona excavada, cu- 


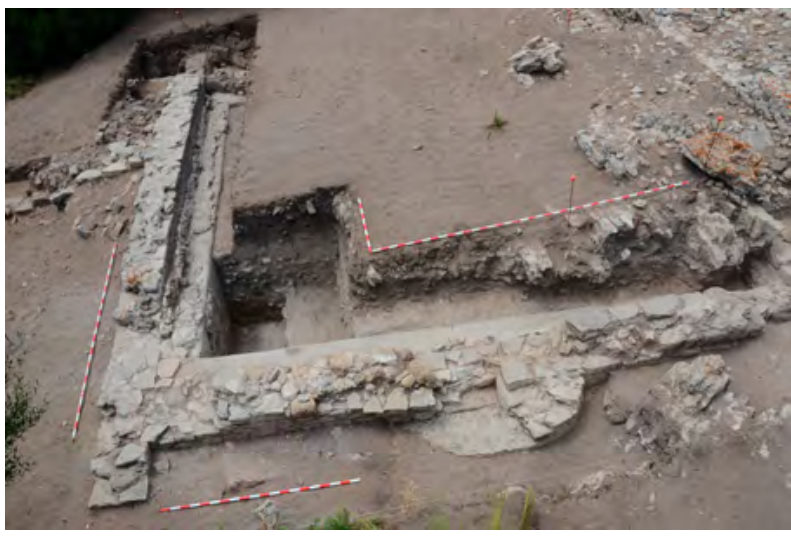

Figura 16.- Vista cenital desde el norte de la H-2, con la delimitación de su perímetro.

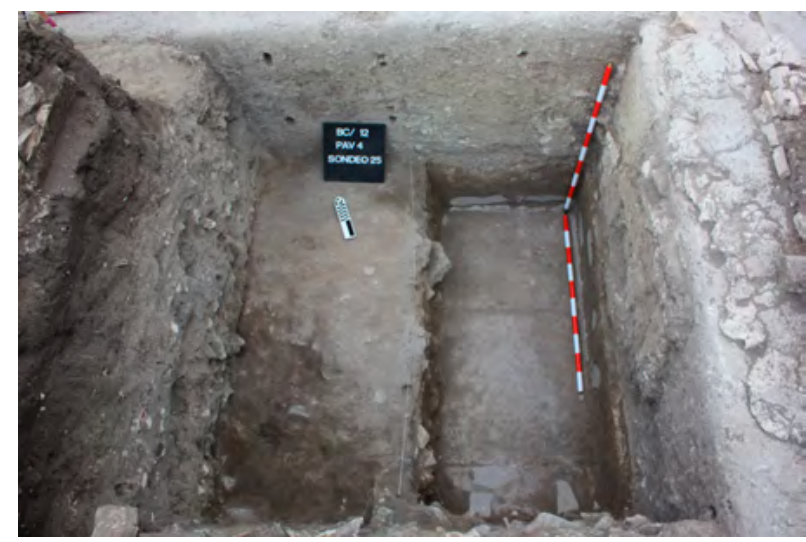

Figura 17.- Detalle desde el sur de la ampliación sureste del Sondeo 25 para documentar la pavimentación de la H-2.

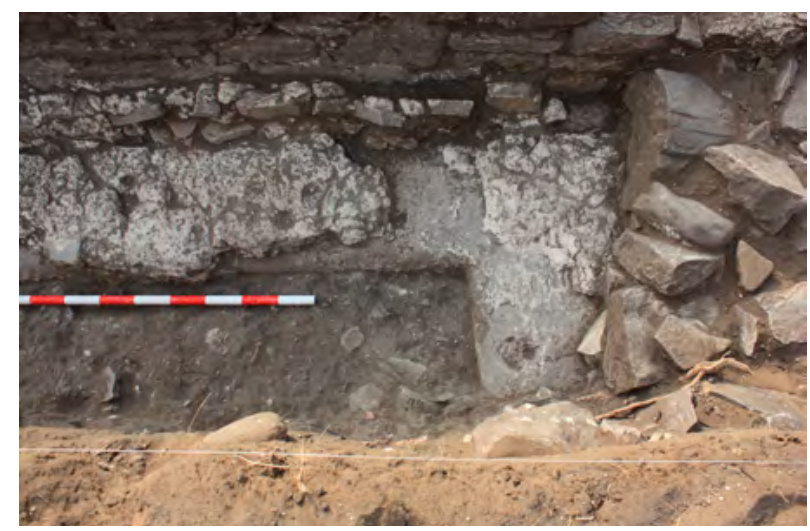

Figura 18.- Vista del ángulo sureste de la H-2, con las placas de revestimiento parietal y la reforma que cubre el hormigón hidráulico original. yas rebabas de argamasa del llagado entre una y otra permiten restituir unas dimensiones aproximadas de unos $60 \mathrm{mts}$. de lado (bipedales) para las mismas, las cuales eran situadas en horizontal, utilizando para ello pequeñas placas marmóreas fragmentadas como elementos de nivelación; un sistema bien conocido además de en Baelo en otras thermae de la Bética como en las de Carteia, cuya piscina $\mathrm{n}^{\mathrm{o}}$ 24 , fechada en el último momento del complejo balneario (is. IV?) presenta las mismas características constructivas en suelo y pared, además de estar dotada de escaleras para su acceso lateral (Roldán, 1992, 108 fig. 26 y 119-120). Asimismo, se advierten en la pared norte y este una serie de orificios realizados ex profeso, de unos 2-3 cms. de dimensiones y otro tanto de profundidad, que deberían estar destinados a albergar los pernos que a su vez anclarían las placas marmóreas del revestimiento parietal, de las cuales in situ solamente resta el arranque de la parte inferior (figura 17). Da la impresión de que dichas placas, de mármol blanco, serían asimismo de grandes dimensiones, al menos en la parte alta, pues la distancia entre estos huecos de encaje es, una vez más, aproximadamente de unos $60 \mathrm{cms}$.

En la parte inferior del revestimiento hidráulico de la piscina y a unos $40 \mathrm{cms}$. sobre el suelo, se detecta un retranqueo horizontal del revestimiento hacia el interior de unos 2-3 cms., quizás realizado para el apoyo de las placas superiores, sin duda de gran peso, aunque sobre todo ello habrá que profundizar cuando se cuente con más datos sobre la estructura. Se ha confirmado la existencia de una reforma en el revestimiento interior de la piscina, consistente en el repellado interior de la misma, el cual a parentemente ocultó los huecos de pernos, por lo que quizás en este segundo momento las paredes no estaban marmorizadas, aunque sí el paramento sobre el reborde exterior de la estructura, en el cual se localizan pequeñas placas alineadas en torno a su pared oriental, de mármol blanco o veteado en rojo, también localizadas hasta la esquina sureste de la habitación (figura 18). La presencia de placas marmóreas sobre el reborde de la piscina y el suelo de la misma en este segundo momento constructivo nos permite confirmar que la estructura mantuvo su uso primigenio hasta su total abandono, o al menos carecemos de evidencia alguna para plantear lo contrario.

La H-2, por tanto, se corresponde con una habitación rectangular de grandes dimensiones, por lo que la interpretamos como una piscina de agua fría 
de un frigidarium de grandes dimensiones. Resta determinar en el futuro su acceso, aunque todo parece indicar que se realizaba desde el sur, por dos motivos. El primero porque arquitectónicamente el usuario se encontraría frente a la puerta la/s hornacinas decorativas, documentadas al norte, en el M-9; y por otro lado por exclusión, porque en los laterales norte y este no hay indicios de escaleras, y al oeste la natatio se encuentra adosada al H-1, situado adicionalmente a mayor altura, por lo que no tiene sentido la ubicación aquí de las escaleras. Más bien, en esta zona, se habría instalado el acceso del agua que debería llenar el estanque.

Los restos excavados de las $\mathrm{H}-1$ y $\mathrm{H}-2$ permiten confirmar que nos encontramos ante el ángulo norte del edificio, pues la continuidad de los muros perimetrales septentrionales de ambas habitaciones define un paramento lineal de gran longitud (de casi 16 metros lineales), al norte del cual no hay estructuras a la misma cota. Asimismo, la piscina de la H-2 está dotada al exterior de contrafuertes, indicando que su paramento de apoyo se corresponde con el exterior del inmueble.

La excavación de la ampliación suroriental del Sondeo 25 permitió, asimismo, documentar los niveles de abandono definitivo de este edificio, que han podido ser fechados con claridad en la segunda mitad del s. V gracias al contexto cerámico del nivel de colmatación de la piscina (U.E. 2512). Concretamente sendas Hayes 87 A de módulos diversos (figura 19, 1 y 2), respectivamente en ARSW $\mathrm{D}^{2}$ y $\mathrm{D}^{1}$, fechadas entre el 450-500 (Hayes, 1972, 136), apareciendo a finales de dicho siglo las formas que evolucionan hacia la 87 A/88 (Bonifay, 2004, 177, fig. 93), más tardías que las nuestras; así como un fragmento de borde de un posible cuenco del tipo Hayes 70 (figura 19, 3), datado habitualmente en la primera mitad de dicha centuria (Hayes 1972, 119). Las restantes formas en $\mathrm{D}^{1}$ (figura 19,4 y 5 ), correspondientes con un pátera (con restos de lañado) y una copa de forma indeterminada, conviven con un cuenco en $\mathrm{C}^{5}$ (figura 19,6), como parece propio de estos contextos (Bonifay, 2004, 175). También se recuperó la orla de una lucerna de disco muy tardía (figura 19,7), posiblemente residual, junto a multitud de cerámicas a mano/torno lento de importación centro-mediterránea (figura 20,15-17), características de contextos del $\mathrm{s}$. $\mathrm{V}_{\text {y }} \mathrm{VI}^{13}$. Entre las

13 La variedad de pastas permite plantear la existencia de varios centros de producción, siendo algunas de ellas (figura 20, cerámicas a torno, y junto a formas abiertas como los lebrillos (figura 20,13), destacan los cuencos carenados en pasta beige/blanquecina (figura 20,14), de la variante $\mathrm{B}-\mathrm{C}$ de los morteros tipo Fulford 2223 , fechados en la primera mitad o mediados del s. V (Bonifay, 2004, 258); además de fragmentos de jarras de cuello estriado de posible producción oriental (figura 20,12) junto a cerámicas pintadas (figura 20,11), excepcionales en estos contextos.

Por último, indicar que las ánforas aparecidas se adecúan bien a momentos avanzados del s. V, caso de la Almagro 51c sudhispánica (figura 20,8), de pequeño módulo, estrecho cuello y posible producción bética, junto a una probable LRA 8 oriental (figura 20,10), envases estos últimos que en Occidente se comercializan entre el s. IV y finales del s. V (Pieri, 2005, 133). Especialmente interesante es la localización de un ánfora onubense del tipo Huelva/La Orden, variante A (figura 20,9), cuya producción y exportación ha sido recientemente objeto de análisis, siendo fechadas habitualmente en la primera mitad del s. VI, aunque como se indica expresamente son escasos los contextos de hallazgo aún (O'Kelly, 2012, 288), siendo ésta la primera constatación de este tipo de exportaciones en el Fretum Gaditanum.

Por todo ello -y teniendo en cuenta los similares resultados obtenidos en los estratos de colmatación de la H-1- consideramos que el edificio estuvo en uso hasta un momento impreciso de mediados o la segunda mitad del s. V d.C.(450-500), siendo éste el momento en el cual se amortizó completamente, abandonándose, al menos, en el área excavada.

Durante la excavación de esta cata en profundidad de la $\mathrm{H}-2$, se produjo un hallazgo excepcional, concretamente los restos de un torso y un pie de una estatua de mármol de grandes dimensiones (figura 21). La escultura de mármol blanco, se corresponde con un personaje masculino de porte atlético, con los rasgos anatómicos muy bien marcados y totalmente desnudo -como también se aprecia en el pie, estante y en una postura intencionalmente forzada, dando la impresión de que cuenta con un brazo flexionado y con otro extendido portando un objeto, por lo que es muy probable que se corresponda con una copia romana de un original griego ${ }^{14}$. $\mathrm{La}$

15) similares a las "toscas" de Cartagena. En el futuro se realizará su caracterización arqueométrica para poder avanzar al respecto.

$14 \mathrm{La}$ escultura y la problemática de la marmorización del edificio está siendo objeto de estudio conjunto con la Dra. Isabel 

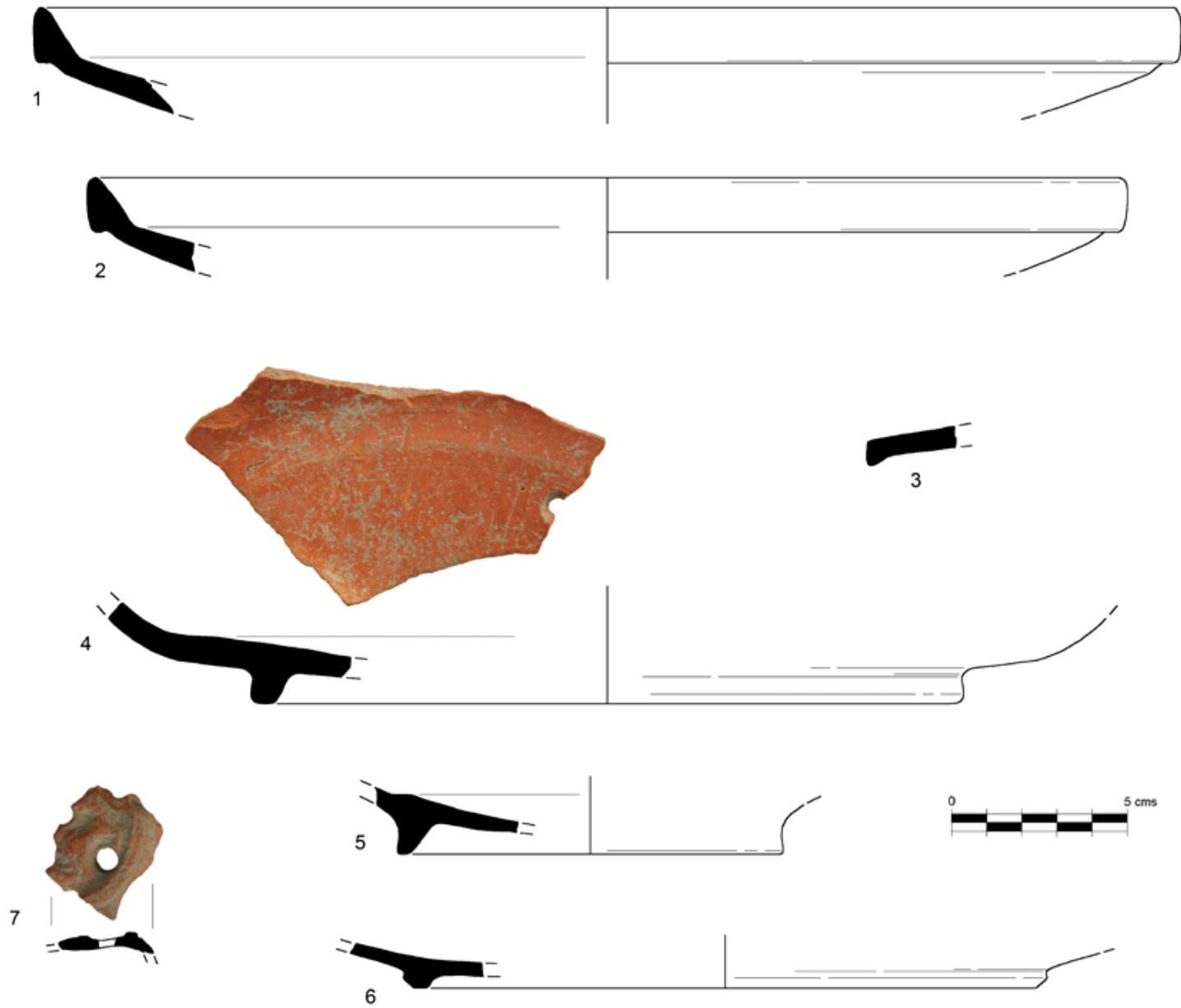

Figura 19.- Selección del contexto cerámico asociado a la colmatación de la H-2 (U.E. 2512).

1.- Borde de Hayes 87 A en ARSW D2 (BC/12/2512/1); 2.- Borde de Hayes 87 A en ARSW D $(B C / 12 / 2512 / 2)$; 3.Borde de posible Hayes 70 (BC/12/2512/3); 4.- Fondo de pátera en ARSW D1 (BC/12/2512/4); 5.- Fondo de copa en ARSW D 1 (BC/12/2512/5); 6.- Fondo de cuenco en ASRW C (BC/12/2512/6); 7.- Disco decorado de lucerna de disco $(\mathrm{BC} / 12 / 2512 / 7)$.

pieza de mayores dimensiones conserva el cuerpo desde el arranque del cuello hasta la rodilla de la pierna izquierda, presentando la otra fragmentada a la altura de la ingle. El brazo derecho, conservado en una menor longitud, da la impresión de encontrarse extendido, mientras que de la tensión de la musculatura del izquierdo parece inferirse que el mismo estaba flexionado. Por su parte, el pie con-

Rodà, del Institut Català d'Arqueologia Classica. Actualmente está siendo limpiada y consolidada preliminarmente por parte de M.L. Millán, restauradora del Conjunto Arqueológico de Baelo Claudia. servado, aparecido a la altura del hombro derecho de la pieza anterior, es el izquierdo, conservando parte del pedestal al que estuvo unido, el cual está asimismo fragmentado. Las dimensiones de la pieza se corresponden con una estatua prácticamente de tamaño natural, ya que las dimensiones máximas del fragmento mayor son de algo más de un metro. Aunque no conserva adherencias perceptibles de pigmentos, se ha guardado todo el sedimento en contacto con la estatua para futuros análisis arqueométricos. Constituye una pieza de notable importancia, tanto por su notable calidad artística 

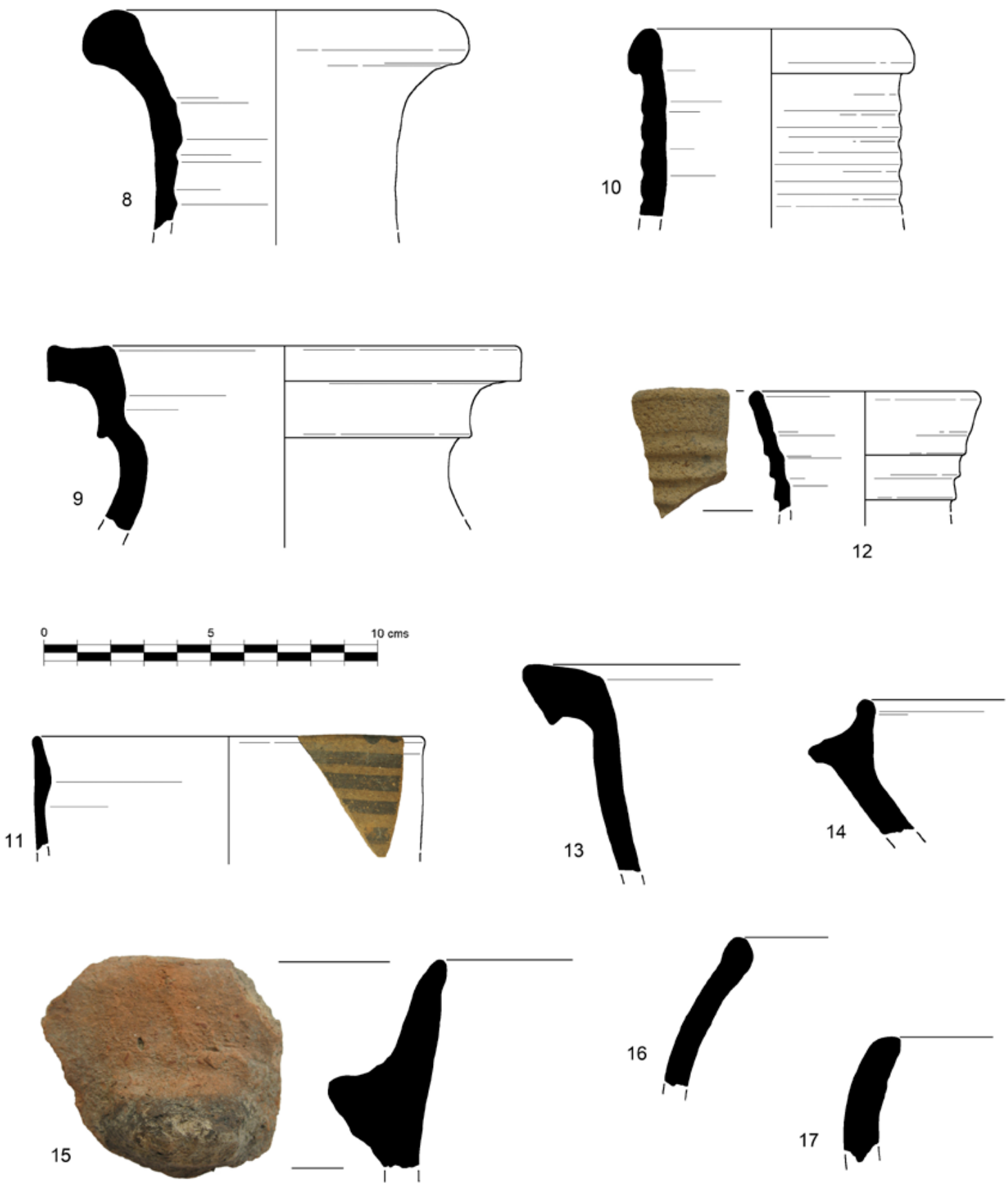

Figura 20.- Selección del contexto cerámico asociado a la colmatación de la H-2 (U.E. 2512).

8.- Borde de ánfora sudhispánica del tipo Almagro 51c (BC/12/2512/8); 9.- Borde de ánfora onubense tipo La Orden (BC/12/2512/9); 10.- Borde de ánfora oriental tipo LRA 8 (BC/12/2512/10); 11.- Borde de cerámica pintada (BC/12/2512/11); 12.- Borde de jarra de cerámica posiblemente oriental (BC/12/2512/12); 13.- Borde de lebrillo en común a torno (BC/12/2512/13); 14.- Borde de cuenco carenado en común a torno (BC/12/2512/14); 15.- Borde de olla a mano con mamelón (BC/12/2512/15); 16.- Borde de olla a mano (BC/12/2512/16); 17 .- Borde de cuenco a mano $(\mathrm{BC} / 12 / 2512 / 17)$. 


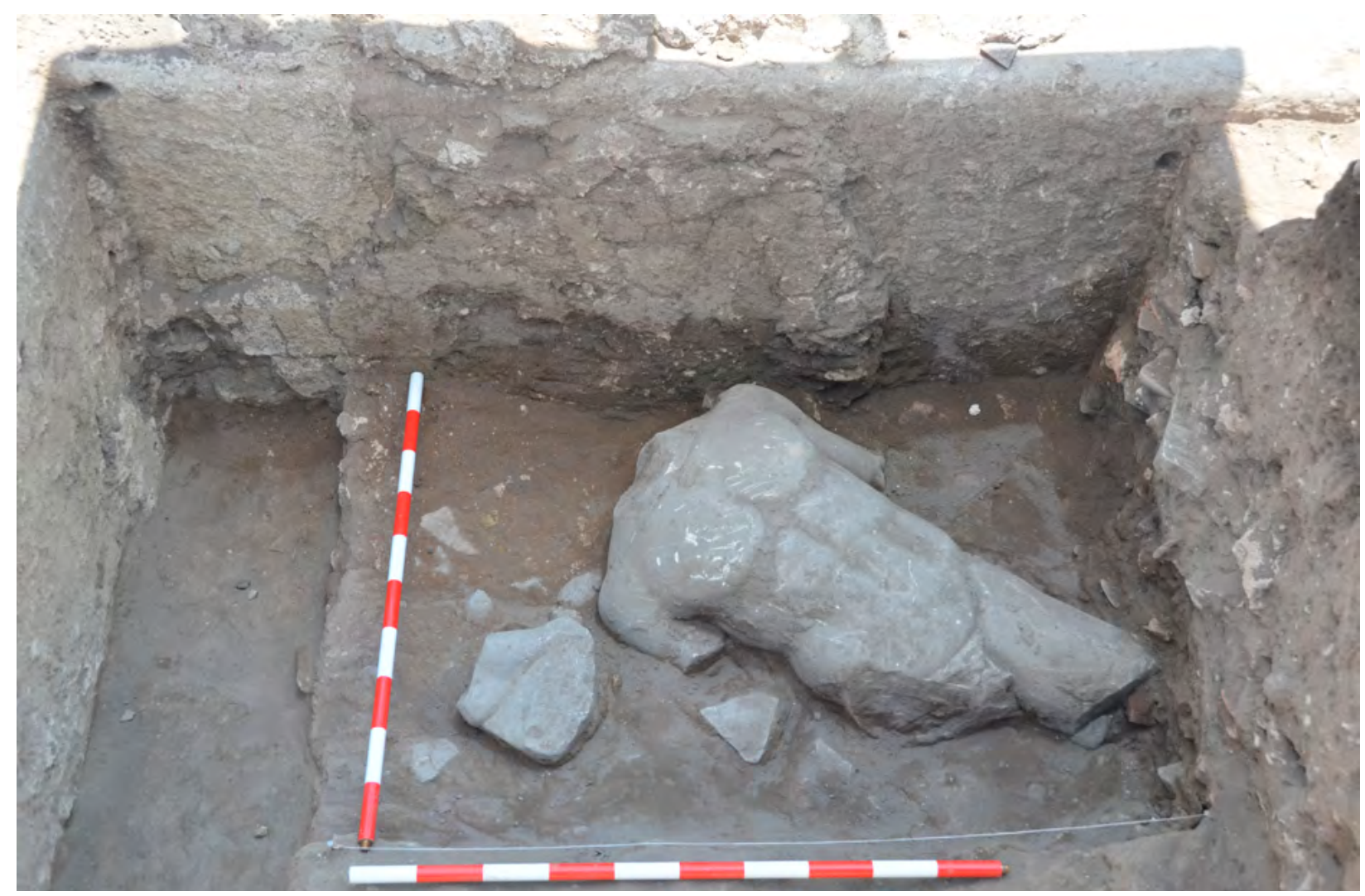

Figura 21.- Detalle de los restos escultóricos aparecidos en el interior de la H-2 (U.E. 2512).

como por el hecho de que en Baelo Claudia la estatuaria conservada se relaciona mayoritariamente con emperadores divinizados, posibles magistrados y/o matronas, la mayor parte realizados con mármoles hispanos, siendo especialmente frecuentes los de Almadén de la Plata y Mijas, correspondientes con obras asociadas a talleres locales (Sillières, 1997, 87, 93, 95, 100, 111, 118 y 137; Loza, 2010).

Parece evidente que debió haber formado parte del programa de decoración escultórica de las termas, quizás de esta propia piscina, pues no olvidemos la existencia de una hornacina junto al hallazgo. El hecho de que se corresponda con un individuo de grandes dimensiones constituye un hallazgo indirecto más para pensar que nos encontramos ante un edificio de carácter público, ya que la ornamentación escultórica de los edificios privados suele ser de dimensiones mucho menores, como ilustra, por ejemplo, el excepcional conjunto escultórico bajoimperial de la villa lusitana de la Quinta das Longas, en Elvas, en el cual las esculturas casi completas conservadas, destinadas a la ornamentación del ninfeo -como la masculina anguípeda o la
Venus sujetando la sandalia- apenas alcanzaban los 50 cms. (Nogales, Carvalho y Almeida, 2005).

Otro elemento muy significativo es la fracturación que presentan las piezas, que parece claramente intencional. Por un lado y tras su limpieza, se ha podido verificar con absoluta claridad que los órganos sexuales habían sido intencionalmente martilleados. Quizás la amputación del pene es lo que habría provocado la fragmentación de la pierna derecha a la altura del pliegue inguinal, y en los pectorales se ha prestado especial atención a la amortización en exclusiva de los pezones. Además de ello, la atenta excavación del contexto arqueológico de hallazgo (U.E. 2512) $)^{15}$ ha permitido excluir que la escultura hubiese sido fragmentada una vez tirada a la piscina, ya que no se ha conservado fragmento alguno de esquirlas o de fragmentos de mármol con ella relacionada. Asimismo, el carácter aristado que presentan las fracturas de la misma, tanto en el cuello como en todas las extremidades,

15 Cuya excavación ha incluido el cribado de la totalidad del sedimento aparecido en las inmediaciones de la escultura. 
parece indicar que la misma fue arrojada al interior de la pequeña natatio inmediatamente después de haber sido fragmentada. No olvidemos que los restos aparecidos se proyectan sobre el perfil meridional del sondeo (figura 21), lo que unido a la escasa superficie excavada (apenas $4 \mathrm{~m}^{2}$ ), permiten intuir que en la parte no excavada de la piscina es muy probable que queden restos de la misma escultura y quizás de otros restos del programa escultórico del complejo termal.

La piscina fue colmatada en un único momento en las fechas anteriormente indicadas (450-500), a pesar de haber definido diversos estratos de colmatación o UU.EE., cuya diferencia únicamente es que se corresponden con vertidos diversos. En el nivel de hallazgo de la escultura los numerosos restos de malacofauna, unidos incluso a instrumental pesquero (anzuelo de bronce) parecen indicar que la estructura se utilizó como receptáculo -vertedero- de residuos diversos, entre ellos aquellos derivados de actividades haliéuticas. Con posterioridad se detecta un potente nivel deposicional de abandono y, sobre él, los derrumbes de las estructuras perimetrales de las habitaciones, ya en época modernocontemporánea.

La fragmentación intencional de la escultura en la segunda mitad del s. V encuentra una explicación relativamente sencilla en relación al cristianismo y a los fenómenos de intolerancia religiosa, que se tradujeron en la eliminación violenta de estatuaria de temática pagana y/o mitológica, como parece ser el caso. Recientes estudios realizados en algunos contextos arqueológicos de la provincia de Córdoba parecen demostrar que esta costumbre estaba ampliamente difundida, al menos en época teodosiana, como se refleja en los casos de las termas privadas de la c/ Duque de Hornachuelos en Córdoba capital, transformadas en iglesia en el s. V; en la conocida villa de Mitra en Cabra, reconvertida asimismo en Iglesia; y quizás en la villa de El Ruedo en Almedinilla (Sánchez Velasco, 2012) ${ }^{16}$. A ellos debemos unir otros en la Hispania meridional, como es el caso de las conocidas esculturas aparecidas en la amortización de la natatio de las termas del foro de Astigi, producida en los momentos iniciales del s. IV. Tal es el caso de la Amazona hallada completa

16 Agradecemos a J. Sánchez tanto la cesión del original de este trabajo en prensa previamente a su publicación como el interesante intercambio de ideas, bibliografía y opiniones sobre estos interesantes fenómenos de amortización de esculturas paganas por cristianos en la Antigüedad Tardía. pero fragmentada, interpretada como resultado de un ocultamiento intencionado, vinculado a un posible episodio iconoclasta en la Écija de la época: se partieron varias esculturas en el mismo momento, y varios fragmentos anatómicos sexuados se recuperaron con profundos cortes transversales (Romo, 2002, 166-168). En Hispania constituye ésta una incipiente línea de investigación, que como se ha visto anteriormente presenta una notable potencialidad. En otros lugares del Imperio, como en el Egipto tardorromano, contamos con mucha más literatura especializada al respecto, que además de ver en estas amortizaciones intencionales fenómenos de intolerancia religiosa-prácticas iconoclastas vinculadas con la destrucción de los ídolos paganos, bien atestiguadas en las fuentes-, plantean tras de sí complejos fenómenos sociales, como la presunción de que las estatuas constituían la encarnación de dioses, semidioses, héroes..., poseyendo por ello las mismas propiedades corporales que ellos: de ahí que se les tratase de aplicar castigos ejemplares similares (como quemarlas o "desmembrarlas" para evitar que respirasen -nariz-, conseguir la pérdida de su autoridad religiosa -amputación de orejas-, y de otras propiedades mediante la damnatio en los ojos o en los pies como sucede en Egipto) para eliminar todo su poder corporal: conocemos casos bien ilustrativos como el famoso episodio del Serapeum de Alejandría en el 392 (Kristensen, 2009, con amplia bibliografía). No olvidemos que nuestra estatua baelonense también está intencionalmente decapitada, y la "desmembración" de la que parece haber sido objeto podría ser interpretada como una acción intencional para aniquilar su poder, no únicamente como un acto de idolatría. No presenta signos,

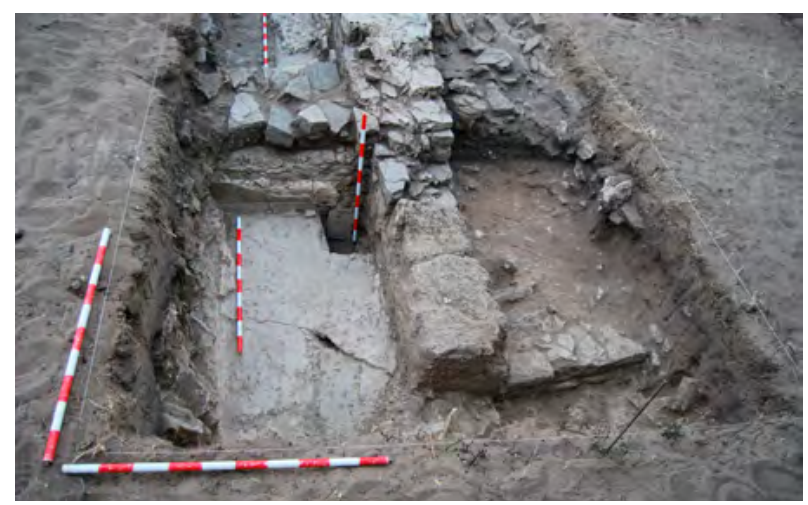

Figura 22.- Vista desde el sur de la habitación calefactada $(\mathrm{H}-3)$. 
como otras, de cristianización intencional mediante grabados simbólicos sobre ella, aunque sobre todas estas cuestiones habrá que volver más adelante cuando dispongamos de más datos sobre el edificio.

Por último, indicar que en la zona sureste del área intervenida (Sondeo 24) se ha podido excavar parcialmente una habitación (H-3), adosada por el sur a la gran piscina, que presenta la particularidad de presentar un suelo de argamasa bajo el cual se localiza un sistema de hipocausis (figura 22). La pavimentación de la $\mathrm{H}-3$ se encuentra aproximadamente a un metro de altura respecto a la de la $\mathrm{H}-2$, habiendo sugerido inicialmente tal hipótesis. La posibilidad de exploración del ángulo nororiental de dicha estancia, gracias a la existencia de un vano cuadrangular en dicho ángulo, ha permitido confirmar que la pavimentación de argamasa es muy potente (unos 10-20 cms.), bajo la cual parecen documentarse dos grandes lajas de caliza (jabaluna posiblemente) que descansan sobre una sustentación que al menos en esta zona parece corresponderse con muros en dirección E-O, a modo de glorias, bien documentadas en yacimientos del norte de la Península Ibérica, un sistema también conocido y alternativo al empleo de las características pilae de ladrillos (Yegül, 1995, 357). No obstante, la abundante presencia de ladrillos de grandes dimensiones embutidos incluso en las paredes (figura 22), los cuales se han recuperado completos en elevado número en los niveles de destrucción del edificio (figura $23 \mathrm{~A}$, con $29 \times 23 \times 6,5 \mathrm{cms}$.) permiten intuir su empleo en el sistema de calefacción, que deberá ser confirmado en futuras actuaciones. No olvidemos el habitual empleo de ladrillos rectangulares completos, muy similares a los hallados en esta actuación, en las estancias calefactadas de las termas urbanas de la propia Baelo, de dimensiones variables pero similares $(28-30 \times 20-22 \times 4,5-6 ; 20-21 \times 14-15 \times$ $3-4,5 ; 23 \times 13 \times 5,5)$, además de los rectangulares $(60 \times 38 \times 6)$ de Munigua o los bipedales y sesquipedales también característicos de las suspensurae en Baelo o Carteia (Roldán, 2008, 754 y 756, Cuadro 1). Asimismo, una gran grieta longitudinal en la parte central del pavimento de la estancia $\mathrm{H}-3$ ha permitido confirmar que el mismo se encuentra sobre-elevado, confirmando que se trata de una suspensura, al tiempo que los ladrillos para crear dobles paredes, con oquedades en sus vértices para ser claveteados en la pared (figura $23 \mathrm{~B}$ ) confirman que algunas de las paredes de estas habitaciones te- nían concamerationes. Esta habitación presentaba las paredes decoradas con grandes placas de calizas, adosadas al enfoscado del muro, en las cuales un retalle longitudinal inferior simulaba la presencia del zócalo. Por último, indicar que la presencia de abundantes placas de mármol y teselas de mosaico en los niveles de derrumbe (UU.EE. 2405, 2408, 2411 y 2412), algunas de ellas insertadas en la cama de argamasa (figura $23 \mathrm{C}$ ), permiten inferir la presencia en las inmediaciones de estancias decoradas con recubrimientos musivarios, posiblemente pavimentales, un detalle edilicio asimismo de gran interés para Baelo Claudia, ya que son prácticamente inexistentes los mosaicos localizados en la ciudad, excepción hecha de los testimonios parciales documentados en las conocidas termas urbanas.

$\mathrm{Al}$ encontrarse adosada la $\mathrm{H}-3$ a la piscina de agua fría, pensamos en interpretarla de manera preliminar como un tepidarium, confirmando que la proyección de las estancias calefactadas se desarrollaría hacia el sur. De ahí que la actuación de limpieza realizada al este no haya deparado los restos de los praefurnia, sino otra pavimentación análoga, que confirma la existencia de otra habitación hacia este sector $(\mathrm{H}-4)$.

Indicar que hacia el este, y en la ladera que suavemente desciende hacia el curso del arroyo, se ha documentado la continuidad de las habitaciones (figura 9), ya que se ha definido la existencia de una estructura (M-7), perpendicular a la piscina del frigidarium, que se proyecta al menos a lo largo de una extensión de seis metros (figura 24). El repellado interior de esta estructura define al menos una habitación hacia el norte (H-5) que debe ser sincrónica -al menos parcialmente- con el uso de las termas, pues la unidad muraria presenta las mismas características edilicias, además de trabar con el muro oriental de la pequeña natatio. Inicialmente pensamos que estas estructuras deben relacionarse con los acondicionamientos de las riberas del pequeño curso de agua, o con la existencia de estructuras portuarias tipo embarcadero, para facilitar el varado de embarcaciones, ya que la bajada de cota (ahora a unos $4 \mathrm{mts}$. sobre el nivel del mar) y la cercanía al arroyo las situaban junto al agua en la Antigüedad.

Se procedió en el verano del 2011 a la conservación preventiva de los revestimientos parietales interiores de algunos paramentos (figura 25) y a la cubrición de los restos con geotextil. Tras un nivel 

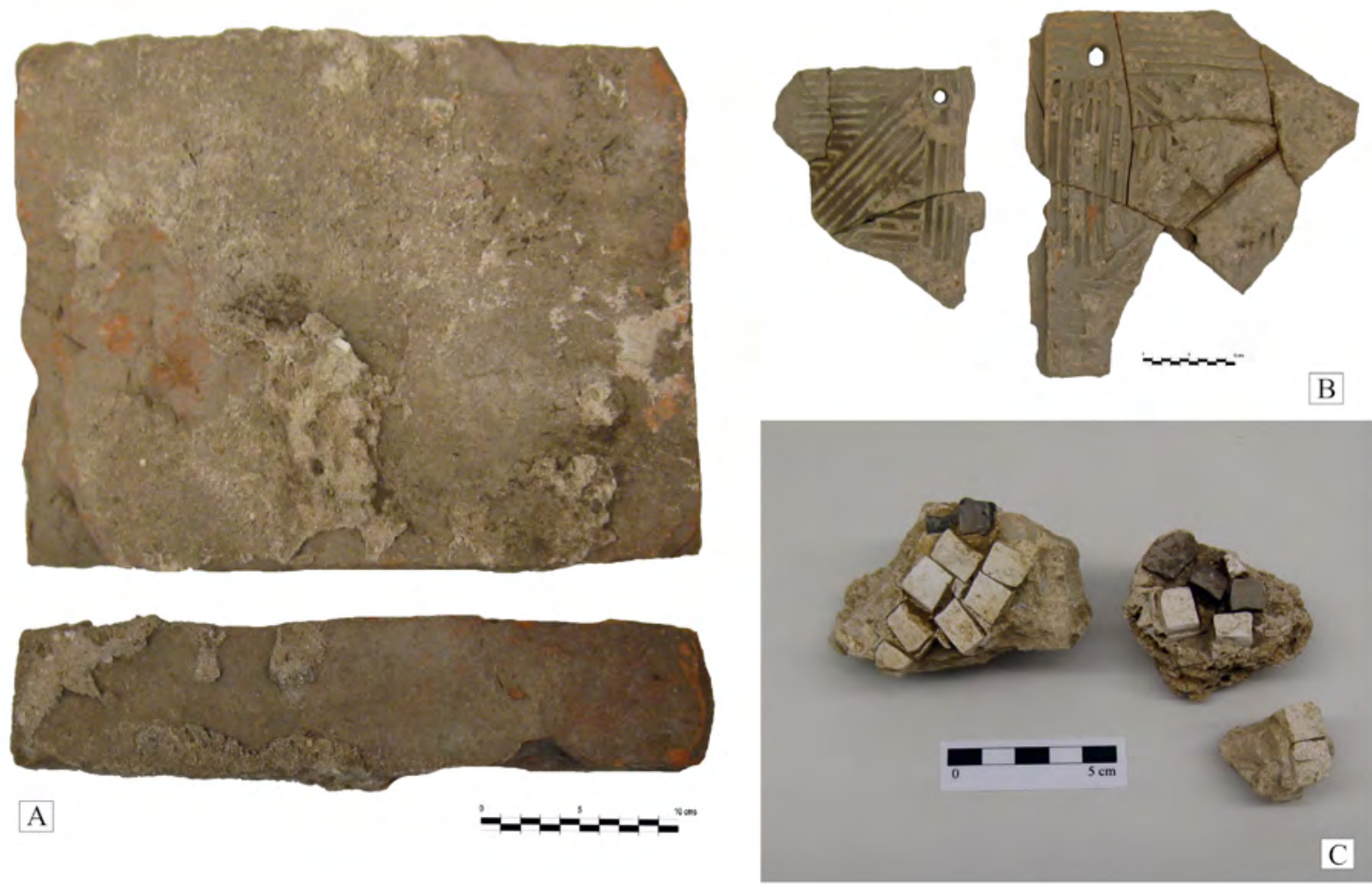

Figura 23.- Ladrillo completo (A.- U.E. 2405), testae de concamerationes (B.- U.E. 2412) y restos de mosaicos (C.U.E. 2405) documentados en los niveles de derrumbe de la habitación H-3.

de abandono debido a génesis natural, detectado en toda la zona y que descarta la reocupación del sector excavado desde el s. V, se documentan potentes desplomes de los muros perimetrales de los edificios, una actividad que acontece a finales del s. XIX o en las primeras décadas del s. XX. Estos derrumbes son de buena parte del alzado perimetral de las habitaciones, ya que los muros se han localizado desplomados sobre los niveles de abandono (figuras 15,16 o 24), especialmente sobre las estancias meridionales excavadas (H-2, H-3, H-4).

\section{VALORACIÓN GENERAL Y PERSPECTIVAS}

En primer lugar, indicar, para finalizar, que la intervención arqueológica realizada durante los años 2011 y 2012 ha permitido documentar el ángulo noreste de un complejo termal, el cual se proyecta hacia la playa y hacia el oeste. El hallazgo de estancias calefactadas y de la piscina de un frigidarium revestida con ornamentación marmórea y escultórica ha permitido aclarar la funcionalidad de este espacio periurbano de la ciudad hispanorromana de
Baelo Claudia, habiendo por ello permitido la correcta consecución de los objetivos planteados en las fases iniciales del proyecto general de investigación.

Los restos aparecidos se corresponden con al menos cinco habitaciones, algunas exhumadas de manera totalmente parcial (H-3 a H-5), todas ellas en un espacio aproximado en torno a los doscientos metros cuadrados - $16 \mathrm{E}-\mathrm{O}$ por $12 \mathrm{~N}-\mathrm{S}$ - (figura 9). Es por ello que se considera aún pronto y arriesgado proponer un esquema de funcionamiento tipológico para el edificio (lineal, axial, anular) y para el itinerario de baño (retrógrado, circular), y tampoco saber si disponía de todas las estancias protocolares para realizar su clasificación (problemática actualizada sobre la nomenclatura en García-Entero, 2005,747 ), aspecto éste que dejamos para futuros estudios, aunque sí nos parece significativo señalar que el baño frío se sitúa al final del recorrido.

Sí podemos avanzar que dispone de una posible cisterna o receptáculo hídrico $(\mathrm{H}-1)$, ya que el mismo se sitúa a una cota mucho más elevada que la restante parte de las estructuras excavadas, y 


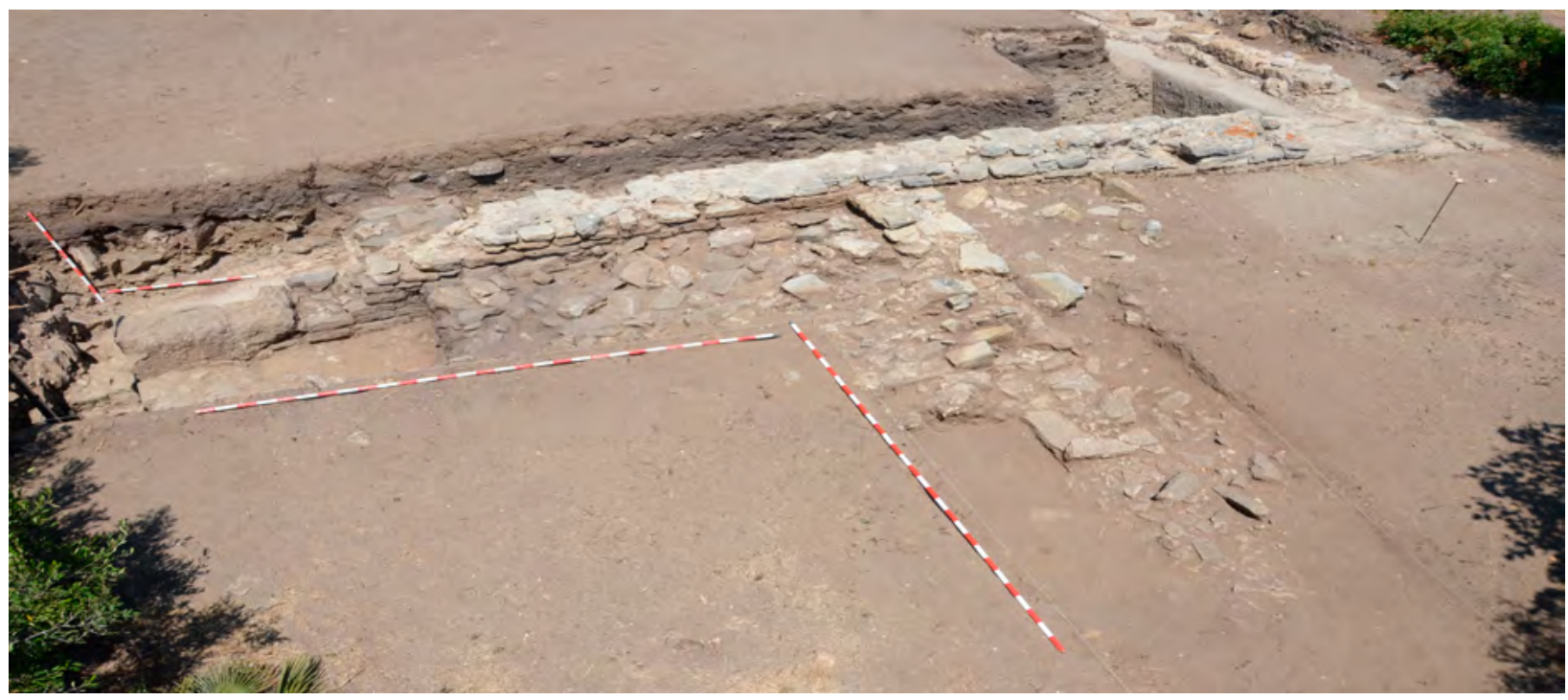

Figura 24.- Vista desde el sureste de las estructuras que se proyectan hacia el cauce del arroyo de las Villas (M-7).

no hay indicios, al menos por el momento, de que constituya otra piscina termal de agua fría. Conocemos algunas cisternas asociadas a conjuntos termales, también dotadas de contrafuertes exteriores y en el límite perimetral del edificio, como sucede con las denominadas termas septentrionales del foro de Complutum (Fernández Ochoa, Morillo y Zarzalejos, 2000, 64), aunque la interpretación más reciente es que este edificio se pudo haber correspondido con un criptopórtico bajoimperial (Rascón, 2000); o la documentada en el yacimiento marroquí de Sidi Bou Hajel, donde un pequeño alveus estaba conectado con una cisterna anexa, formando parte de un balneum privado asociado quizás con una villa (Bernal et alii, 2011).

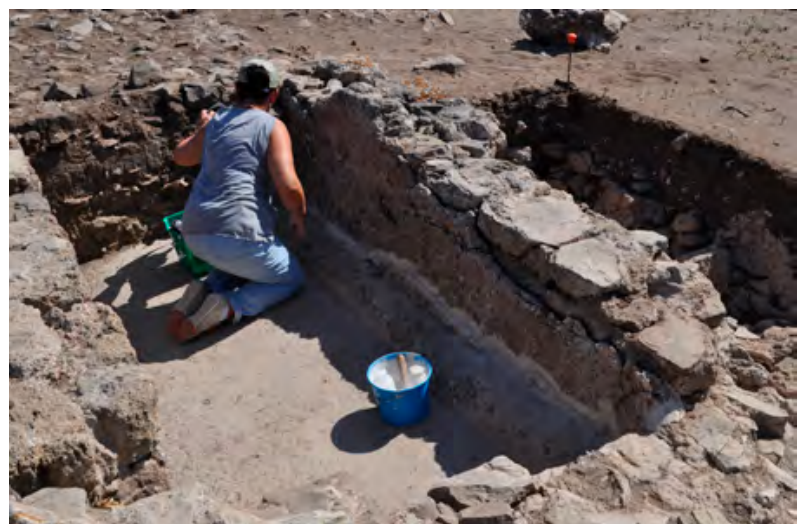

Figura 25.- Consolidación preventiva del revestimiento hidráulico del paramento interior del muro perimetral oriental de la H-1, a cargo de M.L. Millán.
También se ha identificado una piscina de agua fría, que constituye un alveus del frigidarium, y que por su morfología casi cuadrangular, a pesar de sus dimensiones amplias (unos $50 \mathrm{~m}^{2}$ ) consideramos mejor definir como tal más que como una verdadera natatio, las cuales son normalmente rectangulares, de mayores dimensiones y suelen estar al aire libre y aisladas, no pareciendo tal la situación en nuestro caso. Unos buenos ejemplos de natationes son los de las termas de la nova urbs de Italica (Roldán, 1993, 109, fig. 11, P y 115) de 18,4 x 17,5 mts. y planta en forma de T; la recientemente excavada de las termas del foro de Astigi, de unos $140 \mathrm{~m}^{2}(6 \times 23,8$, y una profundidad de 1,29$1,38 \mathrm{mts})$, con cinco peldaños en uno de sus lados cortos (Romo, 2002, 155); o una de las de Carteia, la habitación $\mathrm{n}^{\circ} 6$, rectangular con escaleras en una de sus esquinas (Roldán, 1992, 109, fig. 27, $\mathrm{n}^{\circ} 6$ y 168). Da la impresión por el momento de que es la única piscina de agua fría, a excepción de que las mismas se proyecten hacia el sur o suroeste, teniendo en cuenta la cercanía de las estancias calientes (H-3 y H-4), y otras hacia el este, de momento de funcionalidad indeterminada. No obstante, este detalle no es concluyente, pues en las propias termas de Carteia las diversas piscinas de agua fría no son tangentes entre sí, rodeando las mismas a las estancias calefactadas (Roldán, 1992, 109, fig. 27, $\mathrm{n}^{\mathrm{o}} 6,20$ y 24). Indicar, por último, que algunos edificios balnearios urbanos, como el de Labitolosa, contaron con termas, una de las cuales -las 
llamadas Termas I- contaban con un frigidarium con contrafuertes de refuerzo exterior, en tal caso tres rectangulares y dispuestos sobre el lado largo de la estancia (Fernández Ochoa, Morillo y Zarzalejos, 2000, 62; Sillières et alii, 2000,194). Detalles edilicios por tanto similares a los refuerzos exteriores documentados en el caso baelonense.

Como ya hemos indicado a lo largo del trabajo, diversos aspectos inducen a pensar que no constituyen unas termas privadas o asociadas a una villa, de las cuales conocemos múltiples ejemplos en la Hispania romana (García-Entero, 2005). Por un lado, las amplias dimensiones de las mismas, que parecen hacer pensar en un edificio incluso de mayor tamaño que las termas urbanas de la propia Baelo (Etienne y Mayet, 1971), si tomamos como referencia las dimensiones de la piscina del frigidarium recientemente excavada (unos $50 \mathrm{~m}^{2}$ ) frente a las dos piscinas de la sala de agua fría de las termas urbanas, de respectivamente unos 8 y $17 \mathrm{~m}^{2}$ de superficie (medidas según Sillières, 1997, 154). El tamaño del contrafuerte exterior semicircular de dicho lacus, que duplica en diámetro al de la piscina occidental del frigidarium de las termas interiores, constituye también un argumento a tener en cuenta. Asimismo, como también hemos indicado, el hallazgo de escultura de tamaño natural en ella, perteneciente a un programa escultórico de cierta envergadura, constituye otro elemento a favor de que nos encontremos ante un edificio público.

Esta constatación de unas temas suburbanas en Bolonia, a sumar al medio centenar aproximadamente de edificios públicos balnearios conocidos en la península Ibérica (Fernández Ochoa, Morillo y Zarzalejos, 2000, 63), es de gran interés para la ciudad hispanorromana, pues además de la nueva identificación de un edificio, permite considerar a Baelo entre aquellas ciudades dotadas de dos o más complejos termales, de las cuales conocemos diversos ejemplos en Hispania (Mora, 1981; Fernández Ochoa et alii, 2004) y en la Bética en particular, como Italica (Roldán, 1993) o Astigi (Romo, 2002, 153), entre otras, siendo habitual que las grandes ciudades dispongan de varias thermae y balnea, como sucede con las dos termas públicas y los tres baños privados intra moenia, además de las termas públicas suburbanas, conocidas actualmente en Barcino (Miró y Puig, 2000), algo por otro lado también usual en ciudades norteafricanas al otro lado del Círculo del Estrecho como ejemplifica el caso de Banasa.
Otro elemento a tener muy en cuenta es el carácter suburbano del edificio, que esconde tras de sí un modelo bien conocido y propio de ciudades marítimas, en las cuales el habitual trasiego poblacional y las actividades pesqueras y haliéuticas convertían a estos inmuebles en necesarios para las tareas cotidianas de ocio e higiene. Uno de los mejores ejemplos que ilustran este modelo es el de la ciudad de Pompeya, que contaba con un imponente edificio termal en el acceso a través de Porta Marina, junto a las estructuras portuarias, termas suburbanas construidas a finales del s. I a.C. e inconclusas aún en algunos ambientes en la época de la erupción pliniana (Jacobelli, 1995; Pesando y Guidobaldi, 2006, 88-89). Su ubicación, con imponentes vistas sobre el mar, era muy similar a la del edificio baelonense recientemente identificado. Un ejemplo hispanorromano de mucha mayor envergadura es el ilustrado por las termas públicas del área portuaria de Tarraco (finales s. II/inicios s. III hasta el s.

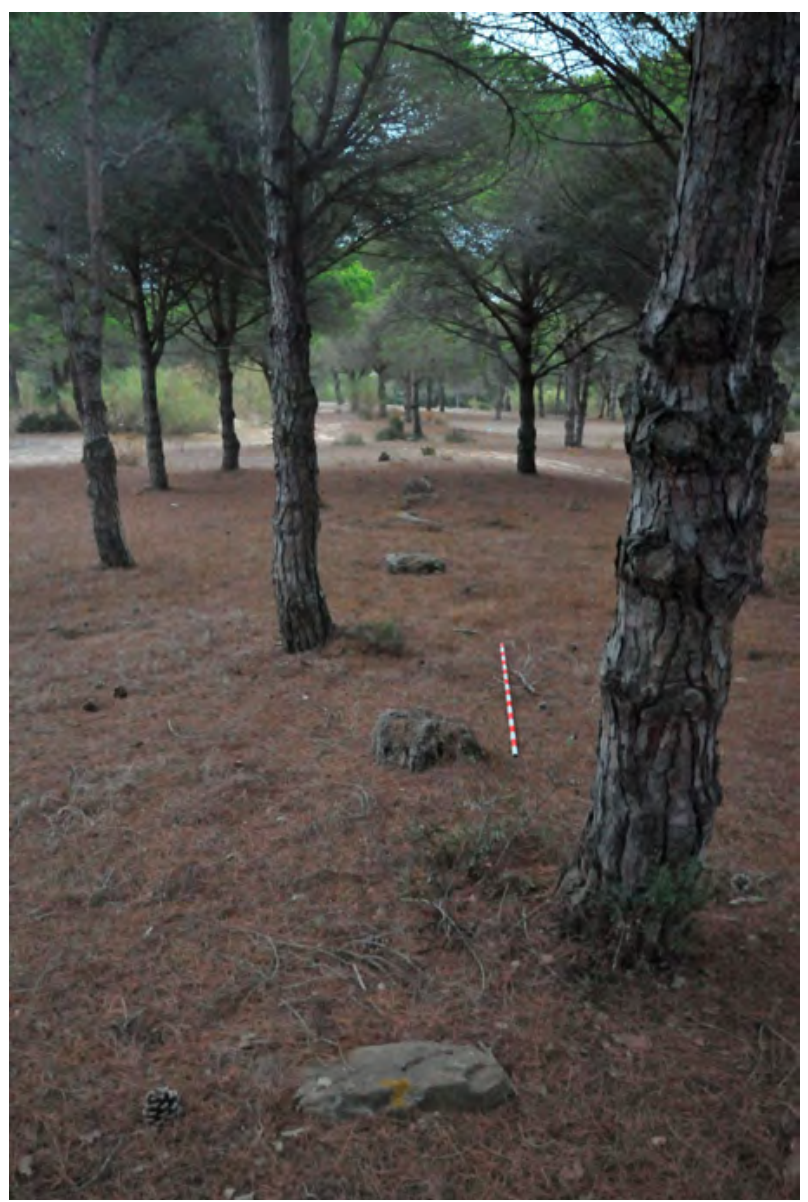

Figura 26.- Sillares alineados en la ladera este del pinar occidental de Bolonia. 
V), excavadas en fechas recientes (Díaz, García y Macías, 2000) y publicadas íntegramente, ajustadas al modelo de terma imperial, con paralelos en las ostienses de Porta Marina y en las llamadas Termas Marítimas (Macías, 2004, eds.). En el caso tarraconense es de reseñar, asimismo, su ubicación junto a la muralla, en el área portuaria, y en las inmediaciones de edificaciones de otra naturaleza, entre ellos almacenes y otros conjuntos con baños privados, que definían el suburbium occidental de Tarraco (Macías, 2004, 169, fig. 155). Una situación, por tanto, prácticamente análoga a la documentada en Baelo Claudia.

Este modelo de termas suburbanas debió caracterizar el paisaje costero de buena parte de ciudades marítimas del Mediterráneo antiguo, documentándose en muchos otros casos como en la propia Barcino -Correu Vell-Regomir 7-9, fechadas desde el s. II en adelante, muy cerca de la muralla- (Miró y Puig, 2000, 177, figura 7). Cronológicamente, los paralelos citados coinciden, grosso modo, con el periodo de actividad que podemos plantear ac- tualmente para estas nuevas termas baelonenses, situado entre la primera mitad del s. II y la segunda mitad del s. V d.C. (100-500). Un abandono de los edificios balnearios en dichos momentos cuadra en general con la dinámica general en Hispania, ya que la fase tardía de las termas se mantiene en buena parte de casos hasta finales del s. IV/inicios del s. V, con algún caso excepcional que se prolonga hasta el s. VI, en Cartagena (Fuentes, 2000, 140).

Interesante también a desarrollar en los próximos años es la relación entre thermae y complejos haliéuticos, pues conocemos casos como Troia en los cuales unas grandes termas se construyeron en el s. III d.C., adyacentes a las fábricas conserveras ("usine Ic"), activas las mismas durante todo el Bajo Imperio, en consonancia con la actividad conservera (Etienne, Makaroun y Mayet, 1994, 121-156). O el balneum del s. IV construido junto al complejo conservero y las cetariae de la isla de Pessegueiro, en la costa atlántica de Portugal (Silva y Soares, 1993, 142-144). Y son evidentes en ambos casos las funciones balnearias de los complejos por la presencia

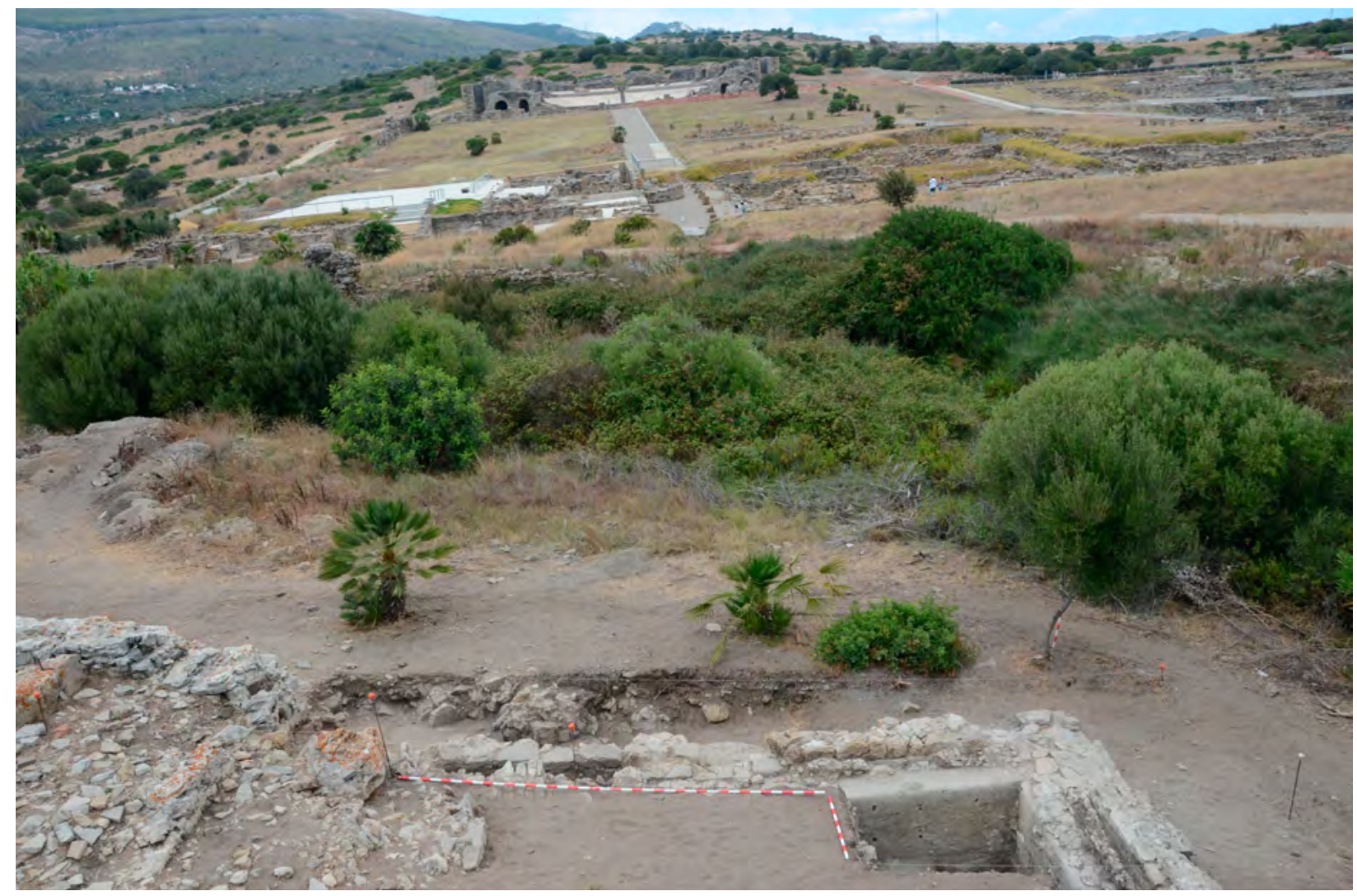

Figura 27.- Vista desde el sur de las estructuras excavadas (H-2) y de su alineación con los edificios localizados al oeste del cardo de las termas. 
de alvei, no pudiendo tratarse de áreas calefactadas relacionadas con la maceración del pescado -como en Cotta o Tahadart-, en la Tingitana atlántica.

Otro de los aspectos importantes ha sido el hallazgo de los elementos de decoración escultórica (figura masculina desnuda) y marmórea utilizados como parte del programa de decoración del edificio. El hallazgo escultórico es de gran interés, además de por lo que aportará cuando se ultime su estudio en curso de desarrollo actualmente, por constituir un elemento cuyo contexto arqueológico ha sido bien definido, sumándose así a los escasos ejemplos de escultura mayor contextualizada, que en Andalucía son muy escasos, siendo los ya citados de la Plaza del Salón de Écija junto a los de la Villa de El Ruedo en Córdoba los más significativos. Ya ha sido señalado por varios autores que el carácter hipogeico de las natationes y estructuras similares propicia la conservación de este tipo de elementos, que en medio urbano suelen ser sistemáticamente expoliados y saqueados para su reconversión en cal. En el ámbito del Fretum Gaditanum su importancia es aún mayor, ya que la decoración escultórica vinculada a edificios termales es muy reducida, limitándose a los antiguos hallazgos en las termas de Carteia, siendo especialmente significativa una estatua de Apolo (Rodríguez Oliva, 1977), recientemente revisada y cuyo contexto preciso de hallazgo ha podido ser atribuido a la esquina noroeste del caldarium (Roldán, 2011). Adicionalmente, la escasa extensión del área excavada de la piscina del frigidarium, menos del $10 \%$ del total, unido al hecho de que los restos escultóricos se adentraban en los perfiles de la excavación, permite plantear como muy probable la documentación de más restos del programa escultórico del edificio cuando avancen las excavaciones arqueológicas.

Asimismo, será importante caracterizar los mármoles utilizados en la decoración arquitectónica por técnicas arqueométricas, pues además de profundizar sobre las canteras de procedencia de los mismos, se podrán aclarar algunas cuestiones de interés, como sucede con el caso del gran labrum marmóreo circular situado al norte del Decumanus Maximus, tradicionalmente atribuido a las termas urbanas por su cercanía (recientemente recogido por Morillo y Salido, 2011, 160, fig. 8), si bien al tratarse de una pieza de notables dimensiones (más de dos metros de diámetro) podría haber sido reutilizado de las termas suburbanas.
Otra de las líneas a desarrollar en el futuro es la relacionada con el aprovisionamiento hídrico del complejo termal. Ya se ha indicado que la excavación parcial de las estructuras no ha permitido aún resolver el funcionamiento del ciclo del agua en el edificio, si bien resulta evidente que las estancias de agua fría debían disponer de canales (posibles fistulae de plomo) embutidas en la parte baja de los paramentos, a la altura de la moldura de cuarto de bocel, como sucede, por ejemplo, en la ya citada natatio astigitana (Romo, 2002, 155). No obstante, encontrándose rodeadas por el curso del arroyo (norte y este) y por la costa (al sur), la única zona de la cual podrían haberse aprovisionado de agua es el área occidental. Y en dicha zona ya sabemos que se ubica una de las fuentes de aprovisionamiento de uno de los tres acueductos de la ciudad, el del Molino de Sierra Plata (Sillières, 1997, 146). Pensamos que más que un ramal meridional de dicho acueducto, que debería cruzar el curso del arroyo de las Villas con la consecuente complicación técnica, es más probable que la ciudad contase con un cuarto acueducto, procedente asimismo de la Sierra Plata, cuyas estribaciones más meridionales presentan suficiente potencialidad hidrogeológica, teniendo en cuenta la tradicional existencia de fuentes. Esta hipótesis, que habrá que verificar arqueológicamente en el futuro con estudios monográficos al efecto, encuentra su primera apoyatura en la localización de una serie de elementos de sillería en la zona del pinar de la playa, a unos trescientos metros al oeste de la zona excavada y en la ladera que desde la necrópolis occidental asciende a Sierra Plata ${ }^{17}$. Se trata de la presencia de sillares, alineados, situados en la ladera de la pendiente que asciende hacia la sierra, prácticamente equidistantes entre sí -entre 5 y 10 mts.- y de los cuales se aprecian al menos una decena en superficie (figura 26). Dichos elementos podrían constituir la sustentación del specus del acueducto, teniendo en cuenta la alineación de los mismos hacia el área excavada (dirección NO - SE).

17 Agradecemos a P. Otero habernos facilitado las primeras referencias al respecto, citando la existencia de varios manantiales al norte de la duna de Bolonia, aprovechados hace un decenio para el suministro hídrico a las viviendas de la Ensenada de Bolonia, así como la localización en la zona de restos de un specus, actualmente no visible. A Myriam Fincker su gentileza al aportarnos datos diversos al respecto, y a Iván García Jiménez por su compañía para localizar estos elementos de sillería, que poco tienen que ver, aparentemente, con un área de funcionalidad funeraria. 
Una necesaria limpieza y georreferenciación de los elementos en la zona, así como una prospección superficial intensiva posiblemente darán muy buenos resultados en el futuro.

Asimismo, es interesante recordar ahora los largos canales documentados a principios del s. XX por P. Paris en la zona (figuras 8 C y $8 \mathrm{D}$ ), que podrían también relacionarse con la distribución hídrica de estos edificios, y cuyo largo recorrido indica que el flujo de agua era notable. Nosotros nos limitamos, por el momento, a plantear esta hipótesis, pensando que el área-fuente estaría en las estribaciones meridionales de Sierra Plata y que el trazado discurriría, al menos, por la ladera donde se han localizado los citados sillares, culminando en la parte baja del suburbium occidental, donde pudo haber desaguado en la $\mathrm{H}-1$ y/o en otras cisternas análogas.

Otro aspecto sobre el cual habrá que profundizar en el futuro es en la orientación de las estructuras excavadas, aparentemente ortogonales con los ejes mayores de los grandes edificios urbanos intramuros. Efectivamente, los muros perimetrales exteriores de la $\mathrm{H}-1$ y de la $\mathrm{H}-2$ están alineados en dirección $\mathrm{N}-\mathrm{S}$ con los cardines, al tiempo que el edificio parece totalmente escuadrado respecto a los inmuebles localizados al oeste del cardo de las termas (figura 27). Es muy probable que ambos edificios termales estuviesen concebidos $a b$ initio en el programa constructivo de la ciudad altoimperial, para lo cual serán necesarios próximamente estudios topográficos de detalle que permitan profundizar en esta propuesta. Además, la cronología de funcionamiento de ambos complejos públicos baelonenses parece prácticamente sincrónica, ya que la rectificación en los últimos años del periodo de funcionamiento para las termas interiores plantea actualmente un funcionamiento entre inicios del s. II y quizás mediados del s. IV d.C. (Sillières, 1997, 163), siendo la fecha final la más dudosa. Es por ello probable que ambos edificios fuesen proyectados o bien por el mismo arquitecto o, en cualquier caso, en fechas similares. El periodo de actividad termal constatado en Baelo Claudia coincide, grosso modo, con el de otras ciudades cercanas como es el caso de la propia Carteia, cuyas termas se fechan entre finales del s. I y el s. IV d.C. (Roldán, 1992, 129).

De gran interés resulta, asimismo, la fase más tardía del edificio, relacionada con el momento en el cual se abandona el uso termal, en la segunda mitad del s. V d.C. Sabemos que las termas en Hispania sufren, durante el Bajo Imperio, todo tipo de reconversiones, en parte propiciadas por la actitud negativa de la Iglesia hacia ellas, pues se veía en los baños una incitación a la lujuria y a la corrupción, a excepción de su uso terapéutico. En Hispania sabemos que algunas de ellas se amplían en estos momentos, ocupando parte del espacio público -como sucede igualmente en las urbanas de Bolonia-, como ilustra el caso de las de Morería en Mérida, siendo mucho más frecuente durante el Bajo Imperio su transformación en iglesias, como así sucede en Ampurias, en Barcelona o en León, fenómeno interpretado por algunos autores como resultado de las donaciones de espacio público a cristianos para la erección de sus conjuntos episcopales o religiosos, siempre en ámbito urbano (Fuentes, 2000, 142). Para otros autores, la aparición de iglesias y/o necrópolis sobre antiguos edificios termales es muy abundante en la Antigüedad, también en Hispania, y tras ello se esconderían fenómenos complejos de carácter religioso, tratando con dichas actividades de exorcizar estos tradicionales reductos de idolatría, previamente corruptos e impíos (Jiménez y Sales, 2004; Sánchez Velasco, 2012).

La escasez aún de evidencias en el caso de las termas suburbanas baelonenses invita a la prudencia, si bien es cierto que la ya comentada fragmentación intencional de la estatua recuperada -con los pezones clara y "limpiamente" eliminados- es una muestra incontestable de la presencia de una comunidad cristiana intransigente en la zona, en momentos avanzados del s. V d.C. Dicha eliminación ritualizada de las esculturas paganas no tuvo por qué llevar aparejada la conversión del recinto en un ambiente cristiano de tipo funerario y/o litúrgico, o al menos carecemos de evidencias arqueológicas por el momento que lo demuestren. Como ya hemos comentado anteriormente, cuando se abandonan las termas en la segunda mitad del s. V ya no hay evidencias de nuevas actividades edilicias ni de otro tipo en la zona hasta época moderna-contemporánea -a excepción de los muros individuados por la geofísica en la parte más superficial (figura $3 \mathrm{~A})$, si es que son tardorromanos-, lo que tampoco excluye la existencia de un posible recinto monacal y/o una iglesia en otras áreas del suburbium baelonense (al modo del conocido ejemplo malacitano de Vega del Mar o del tradicionalmente citado de Ampurias), por lo que habrá que esperar a futuros hallazgos para poder decantarse al respecto.

Como se ha visto al inicio del trabajo, estas termas constituyen un edificio identificado dentro de 
una amplia superficie que hemos definido como el suburbium marítimo de Baelo Claudia, pensando que fue posiblemente la única aglomeración periurbana existente en la ciudad gaditana, dada su potencialidad marinera y su relación con el mar. No podemos, por el momento, confirmar si el único edificio existente en la zona fueron estas grandes termas, aunque tendemos a considerar que no. Parece evidente la necesidad, al menos, de que la ciudad dispusiese de estructuras de carácter portuario, parte de las cuales debieron estar al amparo de este ámbito suburbial. En dicho sentido, otra de las interesantes líneas de investigación para el futuro es tratar de confirmar la necesaria existencia en las inmediaciones de sistemas de contención de las orillas del arroyo, al menos en el tramo final de su desembocadura, así como la presencia de uno o varios puentes para poder acceder desde el suburbium occidental al barrio pesquero-conservero. En este sentido, son muy prometedores los hallazgos de estructuras en la zona más oriental del área excavada, ya que algunos muros (el M-7 especialmente) prácticamente se insertan en la zona inundable, debiendo corresponderse con embarcaderos o zonas de amarre. A pesar de que ha sido descartada la existencia de un faro y/o thynnoskopeion en la zona excavada, parece evidente que este tipo de estructuras debieron existir en la ciudad, por lo que no se descarta su hallazgo en las inmediaciones en los próximos años.

Sí da la impresión de que este suburbium marítimo no tuvo una vocación industrial, como el ya citado de Villa Victoria en el caso de Carteia, cuyas actividades en Baelo Claudia parecerían haber sido centradas y reorganizadas en el barrio meridional intra-murario. Ello no descarta la existencia de alguna cetaria aislada, como quizás suceda con las piletas localizadas en la línea de playa por algunos autores, hacia el oeste del área excavada (Alonso et alii, 2007). Aunque también es cierto que las mismas podrían haber formado parte de instalaciones precedentes, relacionándose con el uso haliéutico confirmado en la zona antes de la erección del complejo balneario -o bien ser posteriores al abandono de las termas, constituyendo fábricas conserveras tardorromanas aisladas y gestionadas por particulares no sometidos ya a la normativa de las leyes municipales-. Por todo ello será necesario profundizar en el futuro sobre el conocimiento y la problemática interna del suburbium, cuyas primeras pinceladas ya han sido trazadas.
Por último, indicar que durante la excavación del año 2011 se localizó una interfaz de destrucción del ángulo sureste de la habitación H-1, la cual comportó el desmantelamiento parcial de una obra de notable porte, con caementa muy sólidos. Esta actividad se realizó en el s. XVI o XVII -a esperas de ultimar el estudio de materiales-, según indica el contexto cerámico y algunas monedas. Estos datos puntuales son de gran interés para el yacimiento arqueológico, ya que de esta época no restan prácticamente evidencias arqueológicas, a pesar de que hay documentación sobre actividades poliorcéticas además de la habitual continuidad poblacional vinculada a las pesquerías. Tal es el caso del proyecto de fortificación de la ensenada de Bolonia de 1664, en época de Carlos II, para prevenir ataques ingleses, que aunque la amplia documentación conservada en el Archivo General de Simancas parece indicar que nunca llegó a ser ejecutado (Sáez, 1999 y 2000 ) ${ }^{18}$, no excluye frecuentaciones en la zona y actividades al efecto. Éste es otro de los aspectos a desarrollar en las investigaciones de los próximos años.

Bibliografía

AA.VV. (2002), Conspectus Formarum Terrae Sigillatae itálico modo confectae, Bonn.

AA.VV. (2009), Jorge Bonsor y la recuperación de Baelo Claudia (1917-1921), Catálogo de la Exposición (Conjunto Arqueológico de Baelo Claudia), Sevilla.

Alarcón, F. (2002), "El agua en la ciudad de Baelo Claudia”, Patrimonio Histórico Hidráulico de la Cuenca del Guadalquivir, Sevilla, 461-493. Alarcón, F. (2007), "La ocupación de la ensenada de Bolonia en época republicana. Estado de la cuestión”, en Arévalo, A. y Bernal, D., eds., Las cetariae de Baelo Claudia. Avance de las investigaciones arqueológicas en el barrio meridional (2000-2004), Sevilla, 225-235.

Alonso, C., Ménanteau, L., Gracia, F.J. y Ojeda, R. (2007), "Geoarqueología y paleomorfología litoral de la ensenada de Bolonia. Primeros resultados y nuevas propuestas”, en Arévalo, A. y Bernal, D., eds., Las cetariae de Baelo Claudia. Avance de las investigaciones arqueológicas en el barrio meridional (2000-2004), Sevilla, 521-538.

Arévalo, A. y Bernal, D. (1999), "La factoría de sa-

18 Agradecemos a I. García Jiménez sus útiles indicaciones relacionadas con esta temática. 
lazones de Baelo Claudia, balance historiográfico, y novedades de la investigación”, Cuadernos de Prehistoria y Arqueología de la Universidad Autónoma de Madrid, 25, 73-127.

Arévalo, A. y Bernal, D. (2006), "Docencia e investigación en Baelo Claudia. Balance de los Cursos Internacionales de Arqueología Clásica (2000-2004)”, Actas de las I Jornadas Internacionales de Baelo Claudia. Balance y perspectivas (1996-2004), Sevilla, 207-232.

Arévalo, A. y Bernal, D. (2007, eds.), Las cetariae de Baelo Claudia. Avance de las investigaciones arqueológicas en el barrio meridional (2000-2004), Sevilla.

Arévalo, A., Bernal, D. y Lorenzo, L. (2007), “Actuaciones arqueológicas”, en Arévalo, A. y Bernal, D., eds., Las cetariae de Baelo Claudia. Avance de las investigaciones arqueológicas en el barrio meridional (2000-2004), Sevilla, 39-70.

Bernal, D. (2009), "El faro romano de Gades y el papel de los thynnoskopeia en el Fretum Gaditanum", en F. Arias, C. Fernández Ochoa y A. Morillo eds., Torre de Hércules, Finis Terrae Lux, Simposio sobre los faros romanos y la navegación occidental en la Antigüedad (La Coruña, junio, 2008), Brigantium 20, 87-107.

Bernal, D. (2011, ed.), Pescar con Arte. Fenicios y romanos en el origen de los aparejos andaluces, Catálogo de la Exposición (Baelo Claudia, 2011-2012), Monografías del Proyecto Sagena 3, Cádiz.

Bernal, D. Arévalo, A., Aguilera, L., Lorenzo, L., Díaz, J.J., y Expósito, J.A.(2007), "La topografía del barrio industrial. Baelo Claudia paradigma de la industria conservera urbana hispanorromana”, en Arévalo, A. y Bernal, D. (eds.), Las cetariae de Baelo Claudia. Avance de las investigaciones arqueológicas en el barrio meridional (2000-2004), Sevilla, 91-224.

Bernal, D. Arévalo, A., Muñoz, A., García, I., Bustamante, M. y Sáez, A. (2011), "Baelo Claudia”, en J.A. Remolà Vallverdú y J. Acero Pérez (eds.), La gestión de los residuos urbanos en Hispania, Anejos de Archivo Español de Arqueología, LX, 65-92.

Bernal, D., Arévalo, A. y Sáez, A. (2007), "Nuevas evidencias de la ocupación en época republicana (ss. II-I a.C.)", en Arévalo, A. y Bernal, D. (eds.), 2007, Las cetariae de Baelo Claudia.
Avance de las investigaciones arqueológicas en el barrio meridional (2000-2004), Sevilla, 237-354.

Bernal, D., El Khayari, A., Raissouni, B., Díaz, J.J., Bustamante, M., Sáez, A.M., Lara, M., Vargas, J.M., y Escalón, D. (2011), "Del poblamiento litoral romano en la Tingitana mediterránea. Excavaciones preventivas en Metrouna y Sidi Bou Hayel”, en D. Bernal, B. Raissouni, M. Arcila, M.Y. Idrisi, J. Ramos, M. Zouak, J.A. López, M. Maatouk, A. El Khayari, B. El Moumni, M. Ghottes y A. Azzariohi (Eds.), Arqueología y Turismo en el Círculo del Estrecho. Estrategias para la Puesta en Valor de los recursos patrimoniales del Norte de Marruecos, Colección de Monografías del Museo Arqueológico de Tetuán (III), Servicio de Publicaciones de la Universidad de Cádiz, Diputación de Cádiz. F.P.C. Servicio de Publicaciones y Dirección Regional de Cultura Tánger-Tetuán del Reino de Marruecos, 405-462.

Bernal, D. y Lara, M. (2012), "Desenterrando a Gades. Hitos de la Arqueología Preventiva, mirando al futuro", Congreso Hispaniae Urbes, Sevilla, 421-471.

Bernal, D., Roldán, L., Blánquez, J., Prados, F. y Díaz, J. J. (2004), "Villa Victoria y el barrio alfarero de Carteia en el s. I d.C. Avance de la excavación del año 2003”, D. Bernal y L. Lagóstena (eds.), Talleres alfareros y producciones cerámicas en la Bética romana (ss. II a.C.VII d.C.), Actas del Congreso Internacional Figlinae Baeticae, British Archaeological Reports, i.s. $1266,457-472$.

Blánquez, J., Bernal, D., Roldán, L., Díaz, J. J., y Prados, F. (2005), "Primeros datos acerca de las posibles instalaciones portuarias de Carteia y de la producción tardorromana de púrpura. Excavación de urgencia en el Callejón del Moro", Caetaria, 4-5, 315-317.

Bonifay, M. (2004), Études sur la céramique romaine tardive d'Afrique, British Archaeological Reports, i.s. 1301, Oxford.

Campos Carrasco, J. M. (2010), "Los suburbios de Onoba Aestuaria", en Vaquerizo, D., ed., Las áreas suburbanas en la ciudad histórica. Topografía, usos, función. Monografías de Arqueología Cordobesa, 18, 267-288.

Díaz, M., García, M. y Macías, J.M.(2000), "Las termas públicas de Tarraco, estudio preliminar", en C. Fernández Ochoa y V. García-Entero eds., 
Termas romanas en el Occidente del Imperio, Coloquio Internacional de Arqueología en Gijón, 5, Gijón, 163-169.

Domergue, C. (1973), Belo I. La stratigraphie, Madrid.

Etienne, R., Makaroun, Y. y Mayet, F. (1994), Un gran complexe industriel a Tróia (Portugal), Paris.

Etienne R. y Mayet, F. (1971), "Briques de Bélo. Relations entre la Mauretanie Tingitane et la Bétique au Bas Empire", Mélanges de la Casa de Velázquez 7, 59-74.

Expósito, J.A. y García, M.E. (2012), "Novedades sobre la pesca y la industria salazonera en el Estrecho. Las cetariae de Carteia”, en Bernal, D. ed, Catálogo de la Exposición (Baelo Claudia, 2011-2012), Monografías del Proyecto Sagena 3, Cádiz, 299-318.

Fernández Ochoa, C., García-Entero, V., Morillo Cerdán, A. y Zarzalejos Prieto, M. (2004), "Proyecto Termas Romanas en Hispania. Balance de una década de investigación (1993-2003)", Cuadernos de Prehistoria y Arqueología de la Universidad Autónoma de Madrid, 30, 167-195.

Fernández Ochoa, C., Morillo Cerdán, A. y Zarzalejos Prieto, M. (2000), "Grandes conjuntos termales públicos en Hispania", en C. Fernández Ochoa y V. García-Entero eds., Termas romanas en el Occidente del Imperio, Coloquio Internacional de Arqueología en Gijón, 5, Gijón, 59-72.

Fuentes Domínguez, A. (2000), "Las termas en la Antigüedad Tardía, reconversión, amortización, desaparición. El caso hispano", en C. Fernández Ochoa y V. García-Entero eds., Termas romanas en el Occidente del Imperio, Coloquio Internacional de Arqueología en Gijón, 5, Gijón, 135-145.

Furgus, J. (1907), "Les ruines de Belon, province de Cádiz (Espagne)", Annales de la Société d'Archéologique de Bruxelles, XXI, 149-160.

Furgus, J. (1908), "Antigüedades romanas en la costa gaditana”, Razón y Fé, XXI, 2, 205-217.

García Jiménez, I. (2008), "Una aproximación al mundo funerario en Baelo Claudia", en Guzmán Armario, F.J. y Castañeda Fernández, V., Vida y muerte en la Historia de Cádiz, Chiclana, 103-124.

García-Entero, V. (2005), Los balnea domésticos -ámbito rural y urbano- en la Hispania ro- mana, Anejos de Archivo Español de Arqueología, XXXVII, Madrid.

Hayes, J.W. (1972), Late Roman Pottery. A catalogue of Roman Fine Wares, London.

Jacobelli, L. (1995), Le pitture erotiche delle Terme Suburbane di Pompei, Roma.

Jiménez Sánchez, J.A. y Sales Carbonell, J. (2004), "Termas e iglesias durante la Antigüedad Tardía, ¿reutilización arquitectónica o conflicto religioso? Algunos ejemplos hispanos", Antigüedad y Cristianismo, XXI, 185-201.

Kristensen, T.M. (2009), "Embodied images, Christian response and Destruction in Late Antique Egypt”, Journal of Late Antiquity, 2/2, 224250.

Loza Azuaga, M.L. (2010), "Nuevas esculturas femeninas icónicas de la ciudad romana de Baelo Claudia (Bolonia, Tarifa, Cádiz)”, Actas de la VI Reunión de Escultura romana en Hispania, Murcia, 119-135.

Macías, J.M. (2004, ed.), Les termes publiques de l'àrea portuària de Tarraco. Carrer de Sant Miquel de Tarragona, Institut Català d'Arqueologia Clàssica, Documenta 2, Tarragona.

Meyer, C. (2010), Informe sobre la prospección geofísica en el área oriental del barrio meridional de Baelo Claudia (Tarifa, provincia de Cádiz, España), Eastern Atlas, Informe 1034/2010, Berlín, inédito.

Miró i Alaix, C. y Puig i Verdaguer, F. (2000), "Edificios termales públicos y privados en Barcino", en C. Fernández Ochoa y V. García-Entero eds., Termas romanas en el Occidente del Imperio, Coloquio Internacional de Arqueología en Gijón, 5, Gijón, 171-178.

Mora, G. (1981), "Las termas romanas en Hispania”, Archivo Español de Arqueología 54, 37-89.

Morillo Cerdán, A. y Salido Domínguez, J. (2011), "Labra de época romana en Hispania", Archivo Español de Arqueología, 84, 153-178.

Muñoz Vicente, A., García Jiménez, I. y Prados Martínez, F. (2009), "Espacios jerarquizados y áreas funerarias en la necrópolis oriental de Baelo Claudia (Tarifa, Cádiz). Nuevas perspectivas de estudio", Jorge Bonsor y la recuperación de Baelo Claudia (1917-1921), Catálogo de la Exposición, Sevilla, 59-77.

Murillo, J.F. y Vaquerizo, D. (2010), "Ciudad y 
suburbia en Corduba. Una visión diacrónica (siglos II a.C. - VII d.C.)", en Vaquerizo, D. eds., Las áreas suburbanas en la ciudad histórica. Topografía, usos, función, Monografías de Arqueología Cordobesa, 18, 455-522.

Nogales Basarrate, T., Carvalho, A. y Almeida, M.J. (2005), "El programa decorativo de la Quinta das Longas (Elvas, Portugal), un modelo excepcional de las villae de la Lusitania", Actas de la IV Reunión sobre Escultura Romana en Hispania, 103-156.

O`Kelly Sendrós, J. (2012), "Las ánforas onubenses de época tardorromana", en D. Bernal y A. Ribera eds., Cerámicas hispanorromanas II. Producciones regionales, Cádiz, 180-205.

Paris, P., Bonsor, G., Laumonier, A., Ricard, R., y Mergelina, C. de (1923), Fouilles de Belo (Bolonia, province de Cadiz) (1917-1921). La ville et ses dépendances, París.

Pesando, F. y Guidobaldi, M.P. (2006), Pompei, Oplontis, Ercolano, Stabiae. Guide Archeologiche Laterza, Roma-Bari.

Pieri, D. (2005), Le commerce du vin oriental à l'époque byzantine (V-VII siècles). Le témoignage des amphores en Gaule, Beirut.

Rascón, S. (2000), “Termas complutenses”, en C. Fernández Ochoa y V. García-Entero eds., Termas romanas en el Occidente del Imperio, Coloquio Internacional de Arqueología en Gijón, 5, Gijón, 237-243.

Rodríguez Oliva, P. (1977), "Estatua de Apollon procedente de Carteia”, Carteya. Revista de Estudios Campogibraltareños, 13, 33-37.

Roldán, L. (1992), Técnicas constructivas romanas en Carteia (San Roque, Cádiz), Monografías de Arquitectura Romana 1, Madrid.

Roldán, L. (1993), Técnicas constructivas romanas en Italica (Santiponce, Sevilla), Monografías de Arquitectura Romana 2, Madrid.

Roldán, L. (2008), "El material constructivo latericio en Hispania. Estado de la cuestión", en D. Bernal y A. Ribera, Cerámicas hispanorromanas. Un estado de la cuestión, Cádiz, 749-773.

Roldán, L. (2011), "Esculturas romanas de Carteia (San Roque, Cádiz). Las excavaciones de Julio Martínez Santaolalla en los años 50”, XI Congreso Internacional de arte romano provincial, 2010, Mérida.

Roldán, L., Bendala, M., Blánquez, J. y Martínez,
S. (2006, dir.), Estudio histórico-arqueológico de la ciudad de Carteia. 1994-1999, Madrid.

Romo Salas, A. (2002), "Las termas del foro de la Colonia Firma Astigi (Écija, Sevilla)", Romula 1, 151-174.

Sáez Rodríguez, A.J. (1999), "Una nueva población en Bolonia, el proyecto de Juan Bernardino de Ahumada de 1664 (I)", Aljaranda, 35, 9-13.

Sáez Rodríguez, A.J. (2000), “Una nueva población en Bolonia, el proyecto de Juan Bernardino de Ahumada de 1664 (II)", Aljaranda 36, Tarifa, 6-10.

Sánchez Velasco, J. (2012), "Cristianización y violencia religiosa en la Bética, tres casos de eliminación de escultura pagana y mitológica en torno a época teodosiana”, El mundo teodosiano (379-455) y el final del Imperio de Occidente, II Coloquio internacional nuevas perspectivas sobre la Antigüedad Tardía, Universidad de Leicester, en prensa.

Sillières, P. (1997), Baelo Claudia. Una ciudad romana de la Bética, Madrid.

Sillières, P., Magallón, A., Fincker, M., Navarro, M., Rico, C., Labarthe, J.M. y Sáenz, C. (2000), "Las termas de la ciudad hispano romana de Labitolosa, avance a su estudio", en C. Fernández Ochoa y V. García-Entero eds., Termas romanas en el Occidente del Imperio, Coloquio Internacional de Arqueología en Gijón, 5, Gijón, 193-198.

Silva, D. Tavares da y Soares, J. (1993), Ilha do Pessegueiro. Porto romano da costa alentejana, Lisboa.

Vaquerizo, D. (2010, ed.), Las áreas suburbanas en la ciudad histórica. Topografía, usos, función, Monografías de Arqueología Cordobesa, 18, Córdoba.

Yegül, F. (1995), Baths and Bathing in Classical Antiquity, Nueva York. 